\title{
Carbon footprint and nutritional quality of different human dietary choices
}

Sara González-García, Xavier Esteve-Llorens, María Teresa Moreira, Gumersindo Feijoo

\section{Accepted Mansucript}

\section{How to cite:}

González-García, S., Esteve-Llorens, X., Moreira, M., \& Feijoo, G. (2018). Carbon footprint and nutritional quality of different human dietary choices. Science Of The Total Environment, 644, 7794. doi: 10.1016/j.scitotenv.2018.06.339

\section{Copyright information:}

(C) 2018 Elsevier Ltd. This manuscript version is made available under the CC-BY-NC-ND 4.0 license (http://creativecommons.org/licenses/by-nc-nd/4.0/) 


\title{
Carbon Footprint and Nutritional Quality of different human dietary choices: A
}

\section{methodical review}

Sara González-García*, Xavier Esteve-Llorens, María Teresa Moreira and Gumersindo Feijoo

Department of Chemical Engineering, School of Engineering, University of Santiago de

Compostela. 15782- Santiago de Compostela, Spain.

*Corresponding author: E-mail address: sara.gonzalez@usc.es

\begin{abstract}
The production of food products presents an outstanding contribution to the global greenhouse gases emission. Since nutrition is a basic human need and humans are able to select the foodstuffs that constitute their diets, dietary choices have a remarkable effect on climate change. In this study, differences on the carbon footprint and nutritional quality of different dietary choices selected from a methodical review have been analysed. In addition, methodological gaps with relevant importance for the outcomes have been also identified. The review includes 21 peer-review journal studies (after a specific selection criteria) deriving on 66 dietary scenarios located in different countries all over the world.

We identified that so-called recommended diets such as the Mediterranean and the Atlantic ones present both high nutritional scores (NRD9.3, a composite nutrient score of a diet) and low carbon footprints. Dietary choices identified in North and West Europe as well as in USA, present the highest carbon footprints. In both European regions, dairy products constitute a basic source of nutrients and high-quality protein. In addition diets adhering to food based dietary guidelines (i.e., healthy diets) do not always derive on lower GHGs emission rates. In general lines, dietary choices rich on plant based products (e.g., vegan, vegetarian as well as Indian and Peruvian) have a better environmental profile than these rich on meat (mostly, ruminant meat). In line with these findings, shifting from ruminant meat to chicken, pork and poultry meat, the iso-caloric substitution of animal based protein by other alternative foodstuffs and the promotion of olive oil ingestion may be coherent with more environmental and healthy diets.
\end{abstract}

We conclude that what we eat plays an important role in the evaluation of the sustainability of people's lifestyles. Thus, although meat and dairy products are the most GHGs-intensive 
foodstuffs, their complete removal from the daily diet could not be realistic in many cultures deriving also on no-healthy habits due the supply of some micronutrients (e.g., calcium and vitamin $\mathrm{D}$ ) below the recommended daily levels.

Limitations were identified in the consulted studies based on the consideration of different system boundaries as well as background uncertainties linked to data sources. Therefore, efforts should be paid into the development of consistent and agreed methods to estimate both carbon footprint and nutritional quality based scores to avoid discrepancies.

Keywords: Diet; Greenhouse gases emission; Healthy diet; Life Cycle Assessment; NRD9.3; Sustainable diet 


\section{Introduction}

The food system is considered one of the most important responsible issues of negative environmental impacts in Europe, mainly in terms of Greenhouse Gases (GHGs) emission, water requirements and land use (Friel et al., 2009; Tukker et al., 2011; Wolf et al., 2011). Moreover, it is expected an increment of impacts from food consumption due to the population and wealth growth, deriving the latter to higher impact diets richer in meat and dairy products (Tukker et al., 2011).

Nutrition is a basic human necessity and food consumption involves a complex system including steps such as food production (e.g., agricultural and farming activities), processing, distribution, final consumption and disposal of waste (Duchin, 2005; Friel et al., 2009). On the other hand, human diets are more than the sum of individual food items. They are complex combinations of different food ingredients, influenced by cultural and regional preferences (de Ruiter et al., 2014).

The access to an appropriate, healthy and suitable nutrition as well as food consumption trends depend on factors such as lifestyle, marketing and, on political and economic aspects (Hawkesworth et al., 2010; Heller et al., 2013). Over the last seventy years, food consumption patterns have considerably changed (Vranken et al., 2014). In this sense, two different stages could be identified in the nutrition transition: the expansion stage, in which consumers increased their energy intake through an augmented intake of vegetable based foodstuffs and, the substitution stage (the current one in industrialised and emerging countries), where carbohydrate rich ingredients (e.g. cereals, roots) are being replaced by vegetable oils, sugar and animal based products (Vranken et al., 2014).

The relevance of the link between the choice of diet, longevity and health is well known and in recent years it is receiving special attention due to the rising awareness by the society (Friel et al., 2009; Thaler et al., 2015). Dietary habits can contribute or prevent diseases such as diabetes, cancer and cardiovascular diseases (WHO, 2003; Wolf et al., 2011). Diets rich on salt, saturated fat and free sugars are example of unhealthy dietary choices (Hawkesworth et al., 2010). In this sense, the low incidence of cardiovascular diseases in the countries located around the Mediterranean Sea has partially been attributed to their dietary habits (Menotti et al., 1990; Duchin, 2005; Estruch et al., 2006). The well-known Mediterranean diet is predominantly 
a plant based diet rich on fruits, vegetables and nuts and low in meat, added sugars, saturated fatty acids and salty snacks (Castañé and Antón, 2017). Olive oil (rich in monounsaturated fatty acids) is the main source of fat that may beneficially influence the risk for these diseases (Estruch et al., 2006). However, it is true that the dietary pattern is only one factor influencing human health amongst others such as physical activity (Wolf et al., 2011).

Moreover, differences on dietary habits can be found between countries (Van Kernebeek et al., 2014). In this sense, Western diets are based on a high intake of meat, dairy products and eggs deriving on higher ingestions of saturated fat exceeding the dietary recommendations (Tukker et al., 2001; Westhoek et al., 2014).

Another topic gaining increasing consideration is the relationship between dietary pattern, resources consumption and environmental impacts. According to Friel et al. (2009), about the $50 \%$ of all food system derived GHGs emission is linked to farming activities mainly due to nitrous oxide (from feeding crops production), methane (from enteric fermentation) and carbon dioxide (from agriculturally-induced change in land use) emissions. In this line, Garnett (2011) and Smil (2002) reported that meat and dairy products are the foodstuffs carrying the greatest environmental burdens and depleting resources. In addition, according to the current population growth trend and foodstuffs intake, it is projected an increment of livestock based products demand of up to $70 \%$ by 2050 (Ran et al., 2017). Thus, plant based diets (lactoovovegetarian diets) are considered more environmentally friendly in comparison with these containing high resources-intensive products, i.e., diets rich on meat (Baroni et al., 2007; Risku-Norja, 2011; Van Kernebeek et al., 2014).

In this sense, research studies focused on designing more environmentally sustainable food production chains remark the necessity of promoting more sustainable dietary patterns (Stehfest et al., 2009; Röös et al., 2015). Besides, dietary changes could be attractive not only from an environmental perspective but also in terms of human health and life expectancy. Health recommendations clearly highlight that less animal based food (specifically beef and pork meat) and more plant based food should be consumed (Stehfest et al., 2009; Thaler et al., 2015). Therefore, the achievement of sustainable food security in the future is linked to a dietary shift from a meat to a plant based diet (Godfray et al., 2010). 
Regarding the estimation of the environmental impact of dietary habits and/or daily diets, it is generally quantified based on data from life cycle assessments (LCAs), which has emerged as a dominant methodological framework. Although LCA method follows international guidelines (ISO 14040, 2006), it presents flexibility allowing the application to a widespread range of systems (Heller et al., 2013). However, the methodological approach followed in the analysis must be clearly defined since it can have a decisive effect on the quality of the results. System boundaries definition, data managed, functional unit and other inherent uncertainties in the method are factors that must be noticeably established specifically in comparative studies.

Numerous studies can be found in the literature considering the environmental footprint (mostly carbon footprint) of European food consumption patterns following an LCA framework (Heller et al., 2013; Van Kernebeek et al., 2014) and even environmental friendly strategies (e.g., refusal of air-transported products, promoting organic production, partial meat replacement by plantbased food, dairy products or mixed food) have been proposed in some cases (Jungbluth et al., 2000; Hallström et al., 2015).

However it is important to take in mind the nutritional quality of the diets as well as the recommended intake levels of proteins and energy when dietary patterns are compared and alternative modifications on the dietary habits are proposed (Röös et al., 2015).

In this study, the carbon footprint, nutritional quality (in terms of Nutrient Rich Diet 9.3 score, NRD9.3) and daily energy intake (i.e. kcal) of different European dietary choices (daily diets) are assessed and compared for several reasons: 1) to determine the relationship between these items (when possible), 2) to identify differences in the same dietary pattern (i.e., vegan and vegetarian diets) between European regions, 3) to answer the question if eating less meat is more environmental friendly maintaining always the nutritional recommendations and 4) to demonstrate the potential environmental benefits of introducing alternative foodstuffs (e.g., superfood) in human nutrition to replace meat consumption.

It is important to take in mind that the number of calories that an average person needs daily depends on several factors, such as the minimum and average dietary energy requirements (Vázquez-Rowe et al., 2017), level of activity, gender, age, weight, geographical location and cultural issues (EFSA, 2009). 
The carbon footprint has been considered as a proxy for environmental impact in line with the studies checked and taking into consideration the awareness from the research community and society on the reduction of GHGs emission and counteracting the climate change effects. To do so, a detailed review has been performed considering LCA based studies available in the literature. To address the comparison, different LCA methodological aspects (boundary and scope of assessments and defining diet) specific for food from a consumption perspective have been established following the recommendations from Heller et al. (2013).

\section{Material and methods}

\subsection{Literature search strategy}

It is well-known the remarkable differences between European countries and the consideration of one representative European diet is not realistic. Different data sources are available giving information regarding food consumption in the European Union either by surveys, household economic expenditure data and food balance sheets from national statistics considering imports and exports (Tukker et al., 2011). A literature review of related studies measuring environmental impacts (specifically carbon footprint estimation) of current dietary patterns that is, considering only daily diets (i.e., complete diets) and excluding the ones focussed on single food items or meals has been performed to ensure scientific quality and to increase the comparability between similar diets as well as following a consumption perspective (Heller et al., 2013). To do so, Scopus, Web of Knowledge (ISI) and Google scholar have been managed considering only English language peer-review studies. According to it, although more than 50 studies have been found assessing environmental impacts of country diets, in total 21 peer-review studies (Wallén et al., 2004; Risku-Norja et al., 2009; Muñoz et al., 2010; Pathak et al., 2010; Tukker et al., 2011; Vieux et al., 2012; Meier and Christen, 2013; Sáez-Almendros et al., 2013; Saxe et al., 2013; Vieux et al., 2013; Werner et al., 2013; Wilson et al., 2013; Scarborough et al., 2014; van Dooren et al., 2014; Röös et al., 2015; van Dooren et al., 2016; Castañé and Antón, 2017; Pairotti et al., 2017; Vázquez-Rowe et al., 2017; Esteve-Llorens et al., 2018; van de Kamp et al., 2018) have been identified fulfilling the selection criteria.

\subsection{Food consumption scenarios}


Food has multiple functions for humans: i) supplying nutrients (i.e., proteins, and vitamins) and energy as well as ii) offering pleasure, culture, and social identity. The function of the dietary patterns under evaluation is to satisfy both items. In this study, 12 different countries have been considered for analysis after the literature search not with the aim of directly comparing the countries, but with highlighting how diets and habits can considerably differ between them, even following the same style diet (e.g., vegetarian, vegan or Mediterranean). Therefore, the different countries have been previously classified in four different zones or clusters (Tukker et al., 2011; Vanham et al., 2013): Western Europe (Germany, France and The Netherlands), Northern Europe (United Kingdom, Sweden, Finland and Denmark), Southern Europe (Spain and Italy) and other countries (Perú, India, USA and New Zealand). Within each of the three European regions or zones there are similarities due to related climatological conditions which can be important in terms of background involved processes (e.g., agricultural or farming production), per capita food consumption ratios and energy intake as well as consumption behaviour for remarkable food groups (e.g., olive oil as fat source in the diet). Finally, to only capture the effect linked to changes in dietary habits and diets composition, additional differences based on foodstuffs production methods (i.e., organic vs conventional) have not been considered for evaluation in this study. Using the literature search, it has been defined 66 European examples of dietary choices which are mentioned as nutritionally healthy diets, current dietary patterns at national level, balanced diets, lifestyle diets and/or environmental sustainable ones. Table A1 provides an overview of the main characteristics of the LCA dietary scenarios proposed for assessment including the identification of the corresponding system boundaries. A detailed description of scenarios per cluster of countries in reported below.

\subsubsection{Dietary scenarios in Southern Europe}

Mediterranean diet is characteristic of the Mediterranean climate area due to the resources available and it is typical of people from Spain, Italy, Northern Africa and Greece (Pairotti et al., 2015). The Southern Europe cluster has included in our classification Spain and Italy as representative countries since no studies have been found in the literature search regarding the remaining involved ones. It is considered an example of healthy and nutritious dietary pattern and recognised by the UNESCO as an intangible heritage of humanity (Castañé and Antón, 
2017). Mediterranean diet does not exclude animal based food but rather admits to low ingestions of them. It is a diet based on a high vegetable intake as well as cereals, fruits and fish. The ingestion of other food ingredients such as meat, eggs, dairy products and sweets is limited (Sáez-Almendros et al., 2013; Pairotti et al., 2015). However it is important to consider that current diet in Mediterranean countries are departing from the traditional one, deriving in different quantities of food groups as consequence of food production globalisation (SáezAlmendros et al., 2013; Pairotti et al., 2015). In this line, Mediterranean diet in Italy is richer on pasta and flour products than in Spain. However, e.g. potatoes are consumed in higher amount in Spain than in Italy.

According to our literature review, not only the Mediterranean type diet receives special attention on Spain (Muñoz et al., 2010; Sáez-Almendros et al., 2013; Castañé and Antón, 2017) and Italy (Pairotti et al., 2017), but also other dietary patterns that currently exit in these countries must be considered due to the population dietary behaviour. The term Mediterranean type diet refers to one with the characteristics previously mentioned, but they could be realized through alternative choices for individual foods. Therefore, it has not the rights on healthy food. The Atlantic dietary pattern is common in Northern Portugal and Galicia (North-western Spain). It is characterised by the abundant consumption of plant based food as well as local and fresh products (seasonal food) minimally processed, being considered as an example of healthy diet (Vaz Velho et al., 2016). The consumption of meat (mostly beef and pork) and eggs is also moderate. Olive oil is used for seasoning and cooking and constitutes the main source of fat (Calvo-Malvar et al., 2016). The main differences with regard to the Mediterranean diet is the largest consumption of fish, red meat, pork, milk, potatoes, fruit and vegetables (GuallarCastillón et al., 2013).

Nevertheless, Mediterranean and Atlantic diet are not the only types of diet as example of healthy ones. Thus, additional dietary behaviours have also been taken into consideration. Vegan and vegetarian dietary patterns are also extended in the Mediterranean area (and in the other clusters under study). The vegetarian diet is based on the consumption of vegetables (any), fruits, dairy products, flour based products and eggs excluding any type of animal based food (Baroni et al., 2007; Pairotti et al., 2015). Regarding the vegan dietary pattern, is also a plant based diet but excluding any foodstuff of animal origin that is, eggs, dairy products, fish 
and meat (Baroni et al., 2007) and instead greater amounts of fortified soy-based milk products, legumes, nuts and seeds are consumed (Meier and Christen, 2013). Although the vegan diet is oversimplified regard to nutrition, it has been considered for analysis since it is relevant when considering sustainable issues (Werner et al., 2013; Castañé and Antón, 2017).

In the case of Spaniards, current Spanish food consumption trends were considered by SáezAlmendros et al. (2013) and two additional dietary scenarios were evaluated contemplating the FAO food balance sheets and the household consumption surveys (Sáez-Almendros et al., 2013). Both scenarios can give an idea regarding the Spanish food trends with regard to the Mediterranean recommendations. Therefore, they have been considered in our review for comparison.

Regarding Italy, in addition to the Italian variant of the Mediterranean diet and de Vegetarian one, Pairotti et al. (2017) considered an Italian dietary scenario based on National average food consumption data, representing the current Italian food habits as well as a healthy diet scenario based on the guidelines defined by the Italian Human Nutrition Society ${ }^{1}$ and daily recommended nutrients intake. Both diet scenarios give an idea concerning the Italian food consumption context.

\subsubsection{Dietary scenarios in Northern Europe}

The Nordic cluster has been constituted in this study by Sweden, Denmark, Finland and United Kingdom. Five studies have been considered for analysis (Wallén et al., 2004; Risku-Norja et al., 2009; Saxe et al., 2013; Werner et al., 2013; Scarborough et al., 2014; Röös et al., 2015), where more than 20 different dietary choices have been identified illustrating real-life situations in these countries. Scarborough et al. (2014) identified six different dietary groups based on questionnaires performed between UK residents taking into account their meat consumption rates: high meat-eaters $\left(\geq 100 \mathrm{~g} \cdot \mathrm{d}^{-1}\right)$, medium meat-eaters $\left(50-99 \mathrm{~g} \cdot \mathrm{d}^{-1}\right)$, low meat-eaters $(<50$ $\left.g \cdot d^{-1}\right)$, fish-eaters, vegetarian and vegan. GHGs emission was estimated for each scenario taking into consideration the values from 94 food commodities as well as adjusting for density and recipes proposal for other different foodstuffs.

Wallén et al. (2004) focussed their study on the fact that consumers need to be given information regarding the environmental sustainability of their shopping choices in order to

\footnotetext{
${ }^{1}$ http://sinu.it/html/cnt/home.asp
} 
identify the most environmental friendly dietary choice. The current Swedish diet (1999) considering food intake data of Swedes was compared with an ideal diet designed according to a sustainable food consumption level taking into account Swedish nutritional recommendations in that time (National Food Administration, 1997; 1999) based on less protein ingestion from animal sources.

Röös et al. (2015) focussed the attention on three Swedish dietary choices: one based on Nordic recommendations and Swedish food preferences, the current average Swedish diet considering food surveys and, a lifestyle diet extended in Sweden based on low carbohydrate and high fat intakes (often from animal source) (Dahlqvist and Höglund, 2009; Amcoff et al., 2012).

Werner et al. (2013) and Saxe et al. (2013) paid attention to Danish dietary patterns. The former identified eight different scenarios (six omnivorous, one vegetarian and one vegan) based on Danish National Dietary Surveys, giving great relevance to the role of dairy products in overall nutrition due to their composition on saturated fatty acids, high-quality protein and calcium. The different scenarios are the following: average dairy or base diet representing the dietary requirements according to the Danish Dietary Guidelines (Astrup et al., 2005), high-dairy (rich on milk based products and cheese), milk-products (excluding cheese products and including marmalade as substitute, typical in Scandinavian meals), cheese-products (no milk products consumption, soft drinks as substitute), non-dairy (all dairy products are excluded, marmalade and soft drinks as alternatives), soy-drink (all dairy products are excluded, soy drinks and marmalade as alternative), vegetarian (dairy products consumption, no meat) and vegan (including soy drinks).

Saxe et al. (2013) assessed three different diet styles that currently exist in Denmark: the average Danish diet and two healthy Nordic ones (Saxe et al., 2006), one based on the Nordic Nutritional recommendations (Nordic Council, 2004) and the new Nordic diet (designed as environmental friendly and with an optimal food composition, according to the Danish dietary guidelines - Astrup et al., 2005, and the OPUS dietary recommendations - Mithril et al., 2012). With regard to Finland, Risku-Norja et al. $(2008,2009)$ assessed Finish food consumption behaviour considering four different scenarios: the average Finish diet, a healthy diet based on 
national health recommendations, a non-dairy and ruminant meat diet replacing the meat from beef and mutton by pork and poultry and finally a vegan diet (Helakorpi et al., 2003).

\subsubsection{Dietary scenarios in Western Europe}

Typical diet composition in Western European countries is characterized by a low ratio vegetal/animal energy, a high ingestion of animal fats and low intake of cereals and vegetables (Tukker et al., 2011). However, an ample dietary variety and nutritional advice are available in the integrated counties. According to the literature search, three countries have been considered for assessment in our study: France (Vieux et al., 2012; 2013), The Netherlands (van Dooren et al., 2014; 2016; van de Kamp et al., 2018) and Germany (Meier and Christen, 2013).

Taking in consideration these studies, different dietary choices have been identified and selected for comparison: an average French diet considering national food consumption surveys (Vieux et al., 2012; 2013), the current Dutch diet based on average Dutch food consumption (van Rossum et al., 2011; van Dooren et al., 2014; van de Kamp et al., 2018), the Dutch variant of the Mediterranean diet, the Scandinavian variant of the Mediterranean diet (known as New Nordic diet), a healthy diet considering Dutch dietary guidelines, a vegetarian diet designed by the authors, a vegan diet, a semi-vegetarian diet -that is, $50 \%$ vegetarian and 50\% following the Dutch dietary guidelines (van Dooren et al., 2014; 2016) and finally, five different German diet scenarios (Meier and Christen, 2013) considering food-based dietary recommendations, average statistical food consumption data (in 2006) as well as a vegan and ovo-lacto-vegetarian dietary styles. Detailed characteristics of all of them are reported in Table A1 in the Appendix.

\subsubsection{Dietary scenarios in other countries}

The awareness regarding sustainable food consumption and sustainable dietary patterns is increasing not only in Europe but also all over the world. Nowadays, the interest on designing healthy diets is commonplace in the society and changes on dietary choices are needed to improve not only health but also to increase the environmental sustainability of the food system (van de Kamp et al., 2018).

Studies can be found in the literature regarding carbon footprint of dietary patterns in Perú (Vázquez-Rowe et al., 2017), New Zealand (Wilson et al., 2013), India (Pathak et al., 2010) and 
USA (Sáez-Almendros et al., 2013). Therefore, these studies have been selected for consideration.

Vázquez-Rowe et al. (2017) proposed 47 scenarios of Peruvian dietary choices considering different geographical, socioeconomic and educational patterns. The interest on this study is outstanding since Peru is one of the most important international culinary destinations in the world (Nelson, 2016). Information of food consumption data was taken from national surveys representing the market baskets of the Peruvian society. The different foodstuffs were grouped in terms of the main fifteen relevant food categories without specifying their intake amount. As relevance, total calorific intake per capita from household preparation and away-from-home preparation was identified. However, the studies were performed without considering cooking stage.

Wilson et al. (2013) developed a detailed assessment based on optimal daily dietary patterns in New Zealand considering nutrients in food, food prices and food wastage with the aim of supporting local and central governments in the promotion of sustainability of food system. Four different dietary scenarios were reported covering all of them the nutrients requirements: lowcost diet (minimizing food cost), low-GHGs diet and two "relatively healthy" diets that is, Mediterranean style diet (following Mediterranean guidelines) and Asian style diet (following the Asian guidelines but excluding the characteristic high-salt sauces).

Typical Indian vegetarian and non-vegetarian balanced diets were evaluated Pathak et al. (2010) reflecting the food habits of the Indian society. To do so, the most relevant common food products in the country were included such as rice, wheat, pulse and mutton (the latter in the non-vegetarian diet). Differences between adult male and female food demand were also identified.

Finally, Sáez-Almendros et al. (2013) proposed for comparison the carbon footprint corresponding to the widespread USA food pattern, titled as Western dietary pattern. According to their description, it is a daily diet rich on dairy products, meat and sweets/sugar (up to 4, 8 and 68 times respectively higher than the corresponding ingestions in the Mediterranean style).

\subsection{Synthesis of the dietary scenarios}


A scenario serves as a hypothesis to be tested regarding a based case or model. In this study, 66 different average dietary scenarios have been selected for comparison, representing all of them current dietary habits of the society in different countries. Shifts in dietary patterns can provide benefits for health and the environment. Thus, our selection can give an idea towards how to score both on health and on sustainability as well as to support consumers to make more informed choices. Protective healthy effects have been detected in numerus studies with regard to the Mediterranean (Duchin, 2005) and Atlantic (Vaz Velho et al., 2016) type diets. Therefore, there is increasing evidence on numerous countries (e.g. Denmark and The Netherlands) where recommended dietary guidelines are being approximated to the Mediterranean type diet (Blauert et al., 2010), promoting an increased ingestion of fruit and vegetables, moderated consumption of dairy products and red meat (beef, lamb, pork, veal) and, substantial reduction of added fats and sugar. Thus, diets based on Mediterranean diet recommendations have been found in the literature in countries such as Italy (S10), Denmark (S33), The Netherlands (S51, S53) and New Zealand (S60). Therefore, differences in this dietary habit between countries will be considered for assessment.

On the other hand, vegetarian and vegan dietary patterns are also widespread all other the world in spite of being considered drastic diets but being fostered (in some cases) by the belief that consumers can make a positive contribution to reduce the climate change effects by replacing animal based products with plant based ones (Carlsson-Kanyama and González, 2009; Werner et al., 2014; Hallström et al., 2015). However, different perspectives have been identified in the literature regarding the term "vegetarian" dietary pattern including or not milk based products, fish and eggs (S9, S23, S42, S48, S49, S62, S65, S66). Thus, this issue will be also analysed.

The effect of the data sources for the estimation of carbon footprint of the dietary scenarios (e.g., diets designed considering food intake recommendations or diets based on food consumption data) will be also studied in detail.

\subsection{Functional unit}

It is well known that the functional unit quantifies an identified function of the system under assessment, allowing direct comparisons between alternative scenarios that meet the same 
function. In this study, the main function of each dietary scenario is the supply of required nutrients/energy offering pleasure, culture, and social identity. Therefore, the comparison in terms of carbon footprint will be initially carried out expressed as $\mathrm{kg}$ of carbon dioxide equivalents ( $\mathrm{kg} \mathrm{CO}$ eq) per person and day. This unit (person-day) allows fair comparisons between different daily consumption patterns. The nutritional quality (in terms of Nutrient Rich Diet 9.3 score, NRD9.3) of different dietary choices will be also estimated per person and day when possible, taking into consideration a total of nine nutrients to be promoted (protein, fibre, calcium, iron, magnesium, potassium, vitamin $A$, vitamin $C$, vitamin $E$ ) and three nutrients to be restricted (sodium, saturated fat and total sugar) following the method proposed by Van Kernebeek et al. (2014). Regarding the daily energy intake (i.e. kcal) differences have been identified between countries even within the same cluster and considering the same dietary pattern. Table A2 in the Appendix reports the corresponding average daily dietary energy consumption per capita as well as the carbon footprint. According to it, the caloric intake is above the recommended 2,000 kcal. day ${ }^{-1} \cdot$ person $^{-1}$ by the Panel on Dietetic Products, Nutrition and Allergies (EFSA, 2009) in European countries. Therefore, the comparisons will be also carried out in a global analysis per 2,000 kcal.day ${ }^{-1}$. person ${ }^{-1}$ for the total diets following the recommendations from van de Kamp et al. (2018). This perspective allows comparing GHGs emission associated with the scenarios independently of caloric intake and giving insight into differences in the carbon footprint due to differences on diets composition. Moreover, the consideration of the daily energy intake as reference unit is recommended by Heller et al. (2013) for diet comparison from a consumption perspective.

\subsection{Estimation of the NRD9.3 score}

One of the main goals of this study is comparing different dietary patterns from a nutritional approach. Although alternative diet quality indexes are available in the literature such as the Health score reported by van Dooren et al. (2014) based on ten indicators (vegetables, fruits, fibre, fish, total fat, saturate fat, trans-fat, free sugars, salt and energy) or the PANDiet index based on the probability of adequate nutrient intake considering 24 nutrients (protein, total carbohydrate, fibre, total fat, saturated and polyunsaturated fatty acids, cholesterol, thiamin, riboflavin, niacin, folate, vitamins $\mathrm{A}, \mathrm{B} 6, \mathrm{~B} 12, \mathrm{C}, \mathrm{D}$ and $\mathrm{E}$, calcium, magnesium, zinc, 
phosphorus, potassium, iron and sodium) described by Verger et al. (2012), in this study it has been considered the Nutrient Rich Diet (NRD9.3) score mainly due to the lack of existing information regarding all the parameters required in the previous mentioned scores and supported by published studies available in the literature (Drewnowski, 2009; Fulgoni et al., 2009; van Kernebeek et al., 2014; Röös et al., 2015; Castañé and Antón, 2017).

Thus, a total of nine nutrients to encourage (protein, fibre, calcium, iron, magnesium, potassium, vitamin A, vitamin C, vitamin E) and three nutrients to limit (sodium, saturated fat and total sugar) have been considered for the estimation of the score taking into account the recommend intake for each nutrient to encourage and the maximum intake for each nutrient to limit reported by the European Food Safety Authority (EFSA, 2010; 2012). In addition, having in mind the trends in Europe towards a Mediterranean diet on a global scale as well as healthy effects derived from Atlantic diet, NRD9.3 scores have also been computed considering the recommended daily average nutrients intake in both diets (Fundación Española de la Nutrición, 2004; Castañé and Antón, 2017). Table 1 displays the recommend intakes for each nutrient to encourage and the maximum ones for each nutrient to limit considering the recommendations previously reported.

Table 1. Recommended nutrients daily intake (RDV). Acronyms: A - RDV from EFSA (2010; 2012); B- RDV from Castañé and Antón (2017); C - RDV from Fundación Española de la Nutrición (2004).

\begin{tabular}{|c|c|c|c|c|c|c|c|c|c|c|c|c|}
\hline & \multicolumn{9}{|c|}{ Nutrients to encourage } & \multicolumn{3}{|c|}{ Nutrients to limit } \\
\hline & Protein & Fiber & Vit A & Vit C & Vit E & $\mathrm{Ca}$ & $\mathrm{Fe}$ & $\mathbf{K}$ & Mg & $\begin{array}{c}\text { Saturated } \\
\text { fat }\end{array}$ & $\begin{array}{l}\text { Total } \\
\text { sugar }\end{array}$ & $\mathrm{Na}$ \\
\hline & $g$ & $g$ & $\mu g$ & $\mathrm{mg}$ & $\mathrm{mg}$ & $g$ & $\mathrm{mg}$ & $g$ & $\mathrm{mg}$ & g & $g$ & $g$ \\
\hline A & 57 & 25 & 800 & 80 & 12 & 0.80 & 14 & 2.0 & 375 & 20 & 90 & 2.4 \\
\hline B & 50 & 25 & $1850^{\mathrm{a}}$ & $1030^{\mathrm{b}}$ & $210^{\mathrm{b}}$ & $1.0-2.5$ & $18-45$ & 3.5 & 400 & 20 & 50 & $1.5-2.4$ \\
\hline C & 91 & 21 & 1404 & 179 & 13 & 1.01 & 13.8 & 3.5 & 237 & 28 & 77 & 1.9 \\
\hline
\end{tabular}

a $700-3000 \mu \mathrm{g} ;{ }^{\text {b } 60-2000 ~ m g ; ~ c ~} 20-1000 \mathrm{mg}$

\section{Results and discussion}

\subsection{Carbon footprint of selected dietary scenarios}


In this study, GHGs emission (in $\mathrm{kg} \mathrm{CO}{ }_{2} \mathrm{eq} \cdot$ person $^{-1}$. day $^{-1}$ ) have been used for the comparison of the environmental impact of different food consumption habits. However, there is a limitation that must be considered and thus, the carbon footprints reported in Table A2 must be interpreted with prudence. The limitation is linked to a methodological approach considered for the estimation of this environmental impact that is, the system boundaries.

In LCA studies the system boundaries define the processes or activities included in or excluded from the analysis. Although a consumption perspective was considered in all of the scenarios and only daily diets were selected, the consumption phase (which could include activities beyond the time of purchase such as transport from retailer to the house, home storage, cooking, management of end-of-life phases and even human excretion) has been only considered in $39 \%$ of the scenarios. Even when this phase is computed, not always the activities included are the same. Human excretion, waste water treatment and solid waste management have been considered by Muñoz et al. (2010) although they were not computed in this review (they represent the $17 \%$ of total GHGs emissions) in S7. On the other hand, cooking in household has not been considered in seven scenarios (S8-S11 and S20-S22). Tukker et al. (2011) excluded from their analysis the consumption phase assuming that its effect (i.e., $\mathrm{kg}$ $\mathrm{CO}_{2}$ eq derived) on the global carbon footprint value is the same regardless the dietary pattern. However, it could not be totally right mainly comparing diets from different countries (Heller et al., 2008; Berlin and Sund, 2010). Moreover, the consumption phase could have an interesting effect in these types of food that derive on small amounts of GHGs throughout their production chain.

The cultivation to retailer approach has been considered by $33 \%$ of the scenarios and the cultivation to farm gate approach, in $28 \%$ of total. Since in the comparison between different diets the system boundaries must be comparable, the evaluations have been firstly performed between studies with similar methodological assumptions.

\subsubsection{Cultivation-to-consumer approach}

The impact of dietary change on GHGs emissions is depicted in Figure 1 considering a cultivation-to-consumer perspective (26 of the 66 scenarios). The diets under this approach have been classified in eight groups such as Atlantic diet (1), Mediterranean diets (2), vegan 
diets (2), vegetarian diets (5), healthy diets (3), diets based on current dietary consumption patterns (6), lifestyle diet (1) and omnivorous diets with different ratios of dairy products consumption (6). According to the results depicted, remarkable differences can be identified not only between diet groups but also within each group. Diets reducing or completely avoiding the ingestion of animal based products such as the vegetarian and vegan derive on the best carbon footprint profiles that is, they are more sustainable in terms of GHGs emissions. This is in line with other studies (Werner et al., 2013; Hallström et al., 2015; Vázquez-Rowe et al., 2017).

Figure 1. Comparative profile in terms of GHGs emission of reviewed scenarios based on a cultivation-to-consumer approach. For references and detailed information about each scenario see Table A1.

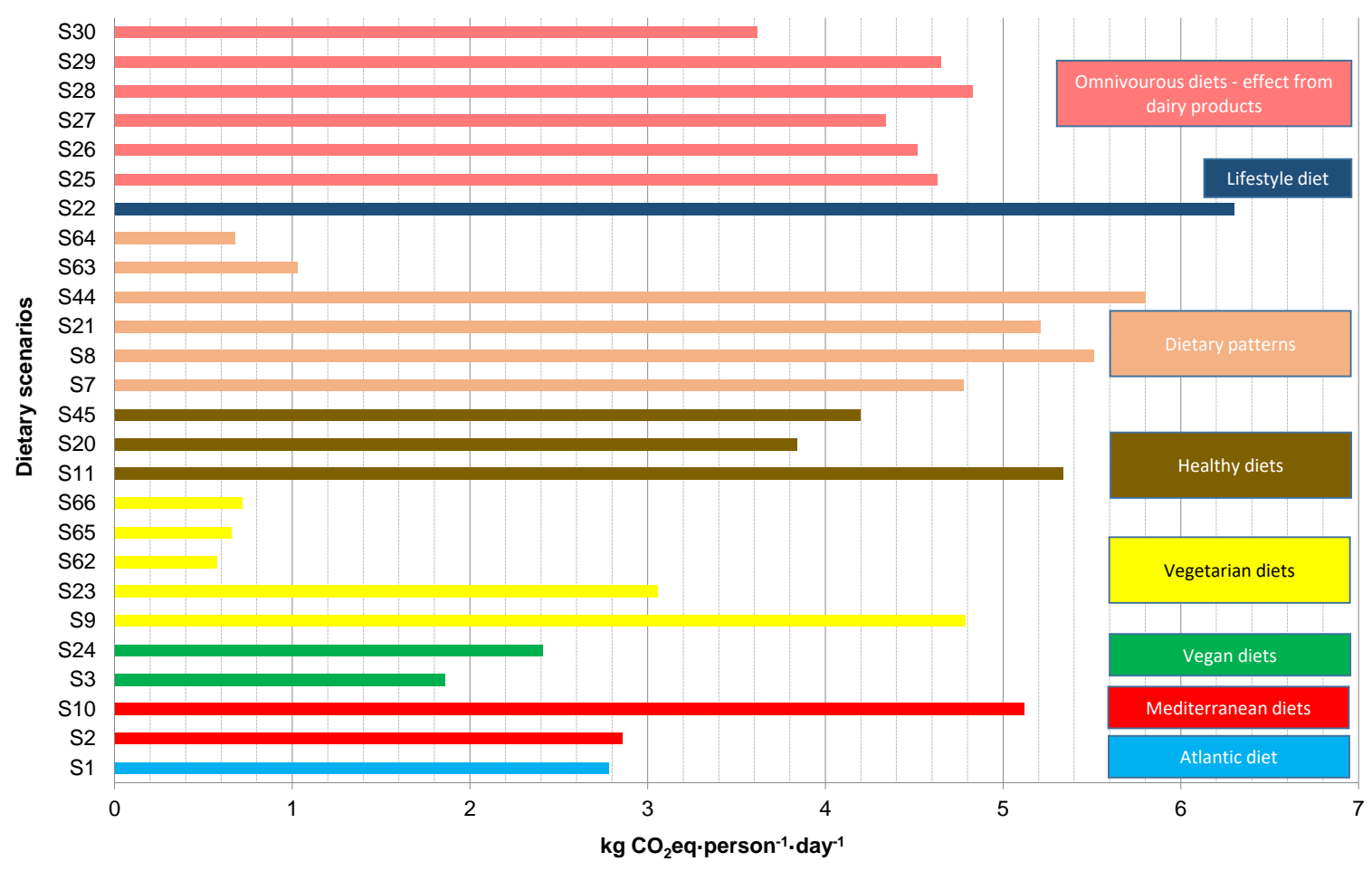

Regarding the Mediterranean diet based scenarios (S2 and S10) a huge difference has been identified between the estimated GHGs emission being 1.8 times higher for S10 with regard to S2. In both scenarios the assessment of the diet was based on Mediterranean diet recommendations (i.e., recommended foodstuffs and servings) following the corresponding food pyramid. However, S10 corresponds to an Italian variance where differences can be identified in the pyramid regarding the food proportions and consumption frequencies (e.g. .potatoes). Moreover, although in both studies the cultivation-to-consumer perspective was established, 
some differences have been identified on this issue. A LCA-Input Output Analysis based model (hybrid method) was applied in S10 including in the estimations the environmental impact of the whole supply chain of food products that is, from production to the disposal of packaging .On the contrary, S2 followed a standard LCA approach. Thus, some impacts from the life cycle of food products were not accounted for in S2 as difference to S10.

The Atlantic diet (S1) reported a carbon footprint score very close (3\% lower) to the Spanish Mediterranean diet (S2). As previously indicated, both diets present the same philosophy regarding the consumption of fruits, vegetables and olive oil. However, Atlantic diet prioritizes seasonal, fresh and local products consumption, deriving on a reduction of GHGs emission.

Regarding the vegan (S3 and S24) and vegetarian (S9, S23, S62, S65 and S66) diets available in the literature, a huge range of fluctuations on the carbon footprint estimations can be identified in Figure 1. It is well-known that diets which most reduce the amount of meat consumption derive on the best environmental profiles (Sonesson et al., 2009; Pathak et al., 2010; Aleksandrowicz et al., 2016) in favouring of vegan and vegetarian diets. It can be identified in S3, S24, S62, S65 and S66 (see Figure 1). However, two exceptions have been detected with S9 and S23. The former corresponds to an Italian vegetarian diet including dairy products and eggs consumption but no fish. In addition, cooking stage is not computed. The latter is a Danish vegetarian diet that as difference to S9 includes fish and food preparation in household. Surprisingly, the carbon footprint reported for S9 is up to 1.6 times higher than S23. However, it can be explained due to differences on the method selected for analysis. S23 followed the standard LCA approach for the estimation of GHGs emission. In the case of S9, the previously mentioned hybrid method was considered, accounting for impacts corresponding to waste disposal and management.

Six daily diets based on current dietary consumption patterns have been also identified and correspond to S7 (Spain), S8 (Italy), S21 (Sweden), S44 (The Netherlands), S63 (India) and S64 (India). According to the revised studies, diets based on current dietary consumption patterns involve a wide array of GHGs emission ranging from $0.68 \mathrm{~kg} \mathrm{CO}_{2} \mathrm{eq}$. person ${ }^{-1}$. day ${ }^{-1}$ (S64) to $5.80 \mathrm{~kg} \mathrm{CO}_{2} \mathrm{eq}$. person ${ }^{-1} \cdot \mathrm{day}^{-1}$ (S44). These diets are mainly based on statistical data of actual food purchases not in recommended food intakes which is expected to derive on worse environmental profiles and higher ratios of food amounts (Castañé and Antón, 2017). 
It is important to have in mind that large amounts of losses and waste can occur in the consumption phase (e.g., cooking step, inedible parts of the food such as bones or peels), which are initially not accounted for in studies where diets are based on recommended intakes. Surprisingly, S63 and S64 - scenarios focused on Indian non-vegetarian dietary patterns including the consumption of mutton and chicken meat, respectively, involve carbon footprints up to 9 times lower than the ones for dietary patterns in other countries such as in The Netherlands (S44), Italy (S8), Sweden (S21) or Spain (S7). In fact, the Indian diets reported the lowest carbon footprint scores in line with vegetarian diets (see Figure 1) in spite of including meat as well as the lowest energy intake per day $(1,739 \mathrm{kcal})$.

One of the most important issues responsible of these outstanding differences between the carbon footprints is the dietary habit which is specifically different between European countries and India as well as only three greenhouse gases were accounted for (methane, nitrous oxide and carbon dioxide). The average quantity of food ingestion per adult person is surprisingly low in Indian studies in comparison with available data found in the literature for other diets (i.e., European ones). According to Pathak et al. (2010), although India has a wide diversity of foodstuffs, Indian consumption habits are based on wheat, rice and pulses as staple foods (225g, 250g and $65 \mathrm{~g}$ per day, respectively) together with vegetables. Meat from mutton is consumed as well as chicken, but in a minor extent (e.g., $30 \mathrm{~g}$ per day). However, European dietary patterns involve larger amounts (on average) of meat consumed per day - mostly red meat (Westhoek et al., 2014; Pairotti et al., 2015; Röös et al., 2015; van de Kamp et al., 2018). Differences also exist regarding the consumption of dairy products (100g per day) being higher in European countries (Westhoek et al., 2014). It is well known that the intensity of GHGs emission from livestock based products that is, meat (and meat based products) and dairy products, is higher in comparison with plant-based products (Garnett, 2011; Westhoek et al., 2014). Therefore, having in mind the Indian habits, it could be expected lower GHGs emission associated to these dietary patterns.

Comparing S63 and S64, a reduction on the carbon footprint is reported in S64, which could be expected in line with the results from Westhoek et al. (2014) since mutton meat is replaced by chicken. According to Westhoek et al. (2014), substituting meat consumption from ruminants by 
monogastric animals contributes significantly to reduce carbon footprint mostly due to the outstanding reduction of methane emissions from enteric fermentation.

Regarding the remaining scenarios, S44 reported the highest carbon footprint $(5.80 \mathrm{~kg}$ $\mathrm{CO}_{2}$ eq. person ${ }^{-1} \cdot$ day $^{-1}$ ) and corresponds to current Dutch consumption patterns. According to that study (van de Kamp et al., 2018), near $130 \mathrm{~g}$ of meat (mainly red meat) and $400 \mathrm{~g}$ of milk based products (including cheese) are consumed, on average per day and person, in that country. Consumption of grain products (including bread), potatoes and pulses is around $230 \mathrm{~g}$, $119 \mathrm{~g}$ and $3 \mathrm{~g}$ respectively. In the case of S21 (Röös et al., 2015) the carbon footprint is lightly smaller $(-10 \%)$ in spite of not so outstanding differences on the consumption trends: $110 \mathrm{~g}$ of meat (mainly pork), $375 \mathrm{~g}$ of dairy products, $280 \mathrm{~g}$ of grain products, $190 \mathrm{~g}$ of potatoes and $16 \mathrm{~g}$ of legumes. Moreover, both diets report similar daily energy intakes. Thus, the minor intakes of meat (being mostly pork) and dairy products in S21 is behind the best profile in terms of GHGs emission.

Regarding S7 and S8, both correspond to current consumption trends in Spain and Italy respectively, being the carbon footprint $\sim 13 \%$ higher in S8. Both are Mediterranean countries (belong to the same cluster), follow the Mediterranean diet recommendations and not so outstanding differences could be expected. The consideration of the mentioned hybrid method in S8 (with an accepted level of uncertainty), different data sources and expected differences regarding the consumption of some foodstuffs (e.g., with regard to bread and pasta and, meat based products the average ingestion is of 1.4 and 10 times more portions per capita respectively than average Mediterranean diet - Pairotti et al., 2015) between both countries are behind the worse carbon footprint in the Italian scenario.

Regarding the Swedish and Dutch dietary patterns (S21 and S44 respectively) report 1.1 and 1.2 times higher GHGs emission than S7. The different consumption habits based on higher dairy products consumption are responsible of these results.

Six Danish omnivorous diets were identified in the literature (Werner et al., 2013) based on different dairy products ingestion, all of them supplying the same daily energy intake to the consumers $(2,197 \mathrm{kcal})$. The interest on these scenarios was based on the analysis of dairy products' role have on the GHGs emission since their ingestion is recommended due to their supply of high-quality protein, calcium and other valuable nutrients. The carbon footprint values 
range from 3.62 to $4.83 \mathrm{~kg} \mathrm{CO}_{2} \mathrm{eq}$. person ${ }^{-1} \cdot \mathrm{day}^{-1}$. The lowest value reported corresponds to the scenario where dairy products are totally substituted by unfortified soy drinks as alternative to milk. It must be highlighted that diets based on soy drinks do not supply the recommended daily levels of some micronutrients such as calcium (up to $40 \%$ lower) and vitamin D ( $60 \%$ lower) between others (Werner et al., 2013). The highest carbon footprint score corresponds to S28, where cheese products are consumed but any other type of dairy product is excluded by means of the ingestion of soft drinks. This option was assessed due to evidences regarding the inverse association between milk and soft drinks consumption (Werner et al., 2013). The production of the consumed amount of soft drinks involves higher GHGs emission than milk based products manufacture (around 1.8 times higher). Moreover, a similar trend as S30 was also identified with regard to the intake of micronutrients, being under the recommended values.

On the other hand, three healthy diets were identified for comparison. An Italian diet (S11), a Swedish diet (S20) and a Dutch diet (S45), following recommended nutrients and food intakes in these countries. The carbon footprint scores reported were 1.4 and 1.3 times higher in S11 with regard to $\mathrm{S} 20$ and $\mathrm{S} 45$, respectively. As previously mentioned, the hybrid method considered for analysis in S11 is the major responsible of these results and it is not possible to identify in which extent. Moreover, these diets belong to different country clusters (SE, NE and WE respectively for S11, S20 and S45) so that inherent differences on foodstuffs consumption and quantities are a reality. Italian diet prioritises bread and pasta as well as vegetables consumption. Regarding the other two, dairy products are of the main nutritional source.

Finally S22 represents a lifestyle diet widespread in Sweden and reported the worse carbon footprint score as depicted in Figure $1\left(6.30 \mathrm{~kg} \mathrm{CO}\right.$ eq. person ${ }^{-1}$. day $\left.{ }^{-1}\right)$. This diet is based on the low ingestion of carbohydrates and the high intake of fat. According to Röös et al. (2015), it includes an outstanding daily consumption of eggs (133g), meat -especially pork (230g), butter $(32 \mathrm{~g})$, cheese $(41 \mathrm{~g})$ and cream (160g) and a surprising reduction of fruits intake (20g). These values (mostly meat and dairy products) are the responsible of its amazing carbon footprint score.

\subsubsection{Cultivation-to-retailer approach}


The consideration of the system boundaries in daily diets assessment till retailers has been assumed in 22 of the 66 reviewed studies. Thus, consumer stage contribution (transport from retailer to household, cooling and food preparation at home) was excluded from analysis. The impact of dietary change on GHGs emissions is depicted in Figure 2. The diets under this approach have been classified in seven groups such as Mediterranean diets (2), diets based on current dietary consumption patterns (8), vegetarian diets (2), vegan diets (2), diets based on different ratios of meat consumption (4), sustainable diet (1) and healthy diets (3).

Figure 2. Comparative profile in terms of GHGs emission of reviewed scenarios based on a cultivation-to-retailer approach. For references and detailed information about each scenario see Table A1.

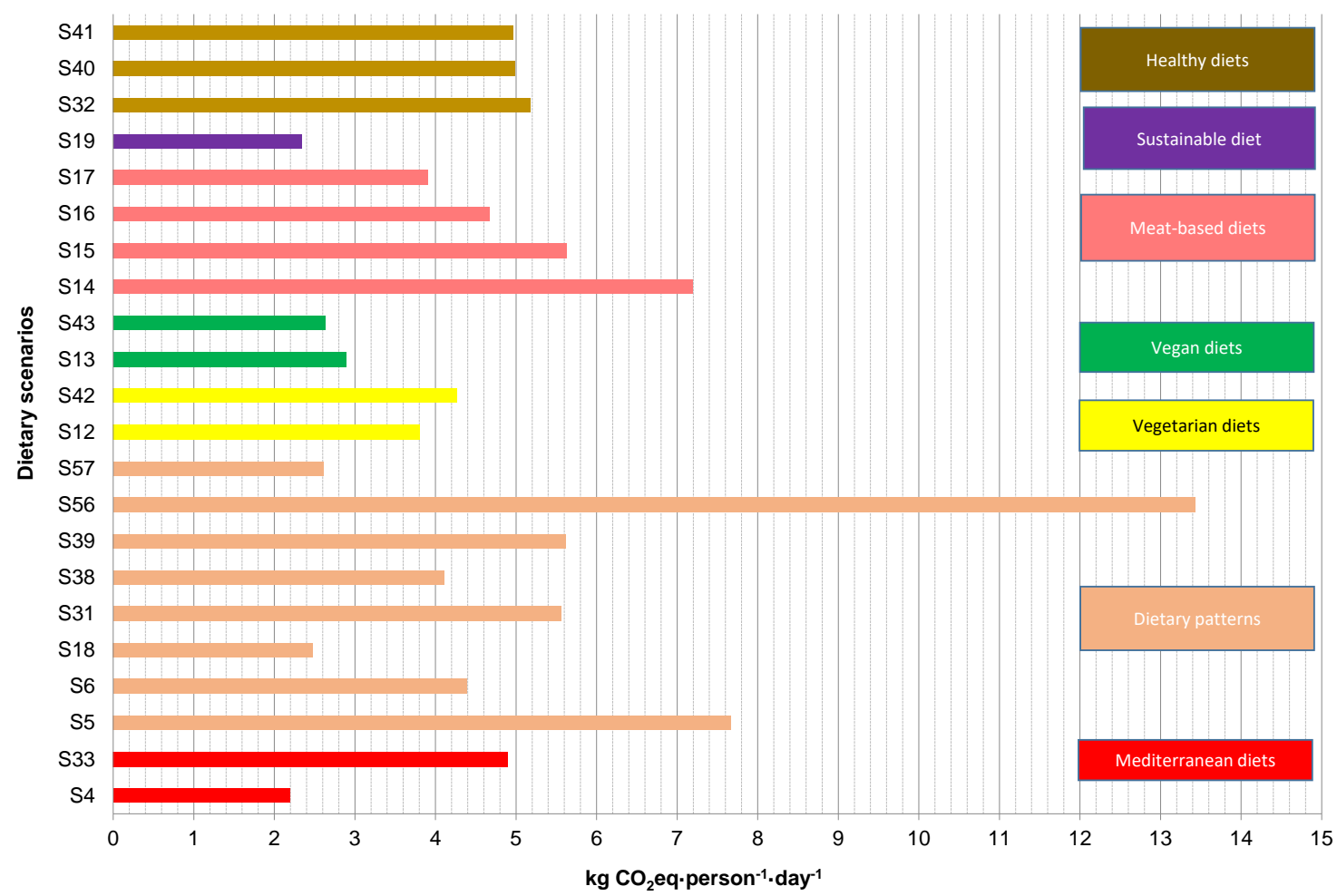


According to the results depicted, light differences can be identified not only between diet groups but also within each group although a specific scenario (S56) reports the worst profile. Once again, diets based on the ingestion of plant based products (vegetarian and vegan) derive on the best carbon footprint profiles (S12, S13, S42 and S43). The diet defined as sustainable (S19) derived on the second best score of GHGs emission, close to the ones corresponding to vegan and vegetarian diets. Finally, one of the Mediterranean diets (S4) can be identified as the most environmentally sustainable within the set in terms of GHGs emission.

Having a look into the selected scenarios based on current dietary patterns, they correspond to very different dietary habits: Swedish (S18), Peruvian (S57), American (S56), Danish (S31), French (S38), German (S39) and Spanish (S5 and S6). The reported values of carbon footprint

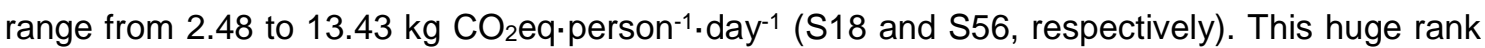
of values considerably depends on the consumption habits, the daily energy intakes as well as carried uncertainties regarding the use of different data sources and possible assumptions (e.g., consideration or not of beverages). In the case of S18, it corresponds to consumption trends in period 1998-2000. Meat based products and dairy products were identified as environmental hotspots due to their outstanding daily consumption ( $330 \mathrm{~g}$ and $460 \mathrm{~g}$ per person, respectively). The authors proposed sustainable food consumption (S19), involving a reduction of $36 \%, 50 \%$ and $30 \%$ of meat, cream and cheese intakes, respectively. Therefore, around $6 \%$ of improvement in carbon footprint was achieved (S19).

Regarding the American dietary pattern (S56), it is based on a large intake of meat (365g) and dairy products $(700 \mathrm{~g})$ - it is the scenario with the largest ingestions of both foodstuffs, which is responsible of the surprising GHGs emission. Thus, its worse environmental profile could be expected.

Danish and German dietary patterns (S31 and S39) are line in terms of GHGs emission (5.56 and $5.62 \mathrm{~kg} \mathrm{CO}$ eq.person ${ }^{-1} \cdot$ day $^{-1}$ ) although belong to different clusters (NE and WE) and reported different daily energy intakes (1.4 times higher in S31 than S39). Dairy products (378g) and meat $(205 \mathrm{~g})$ are the most consumed food products in S31 and the main responsible of carbon footprint. In the German diet, both are consumed in a minor amount ( $253 \mathrm{~g}$ and $103 \mathrm{~g}$, respectively). Thus, differences on the score are mainly affected by background processes. 
French dietary pattern (S38) presents an environmental behaviour and daily energy intake close to the Spanish one (S6) based on data from consumption surveys from the Spanish Ministry of Agriculture, Food and Environment (Sáez-Almendros et al., 2013). Consumers from both countries reported similar consumption habits according to the consulted statistics.

Differences of up to $43 \%$ were identified between the Spanish diets designed from consumption patterns, S5 and S6. The consideration of different consumption data is belong that outstanding variance.

Finally, Peruvian consumption habits were also included in the comparison (Vázquez-Rowe et al., 2017), reporting a value aligned to those corresponding to vegan diets in spite of including meat and fish consumption. However, Peruvians consume meat and dairy products in a minor extent than Europeans and Americans (100g and $73 \mathrm{~g}$, respectively), promoting the ingestion of fruits, vegetables and grains.

With regard to vegan and vegetarian diets, two different scenarios (one corresponding to UK and the other to Germany) were identified per diet group. Variations within each group were around $10 \%$ and the main rationale behind them could be associated to different foodstuffs ingestion (i.e., doses) and habits but mostly, to the use of different data sources.

Three healthy diets were identified under a cultivation-to-retailer approach corresponding to case studies of Denmark (S32) and Germany (S40 and S41). In all of them, sanitary recommendations were followed for their design and differences on the corresponding carbon footprints lower than $4 \%$ were identified as depicted in Figure 2. S41 derived on the best profile because besides healthy recommendations, ecological and social constrains were also considered prioritizing organic food. However, the improvement associated to the profile was almost negligible.

Finally, four diets were included in the assessment considering different food consumption habits identified in United Kingdom regarding the ingestion of meat. High-, medium-, low- and no-meat consumers were analysed (S14, S15, S16 and S17). As expected, the GHGs emission increased in line with the reduction of meat portions ingestion.

\subsubsection{Cultivation-to-farm gate approach}


This approach from cultivation to farm gate, excluding all the stages that occur beyond the time of production was considered by 18 of the 66 daily diet scenarios chosen for analysis. The interest on these studies should be focussed on identified how food groups affect the carbon footprint, mandatory information for the design of sustainable diets, assuming that further activities have similar impact regardless the dietary habit. Figure 3 displays the comparative profiles in terms of carbon footprint.

Figure 3. Comparative profile in terms of GHGs emission of reviewed scenarios based on a cultivation-to-retailer approach. For references and detailed information about each scenario see Table A1.

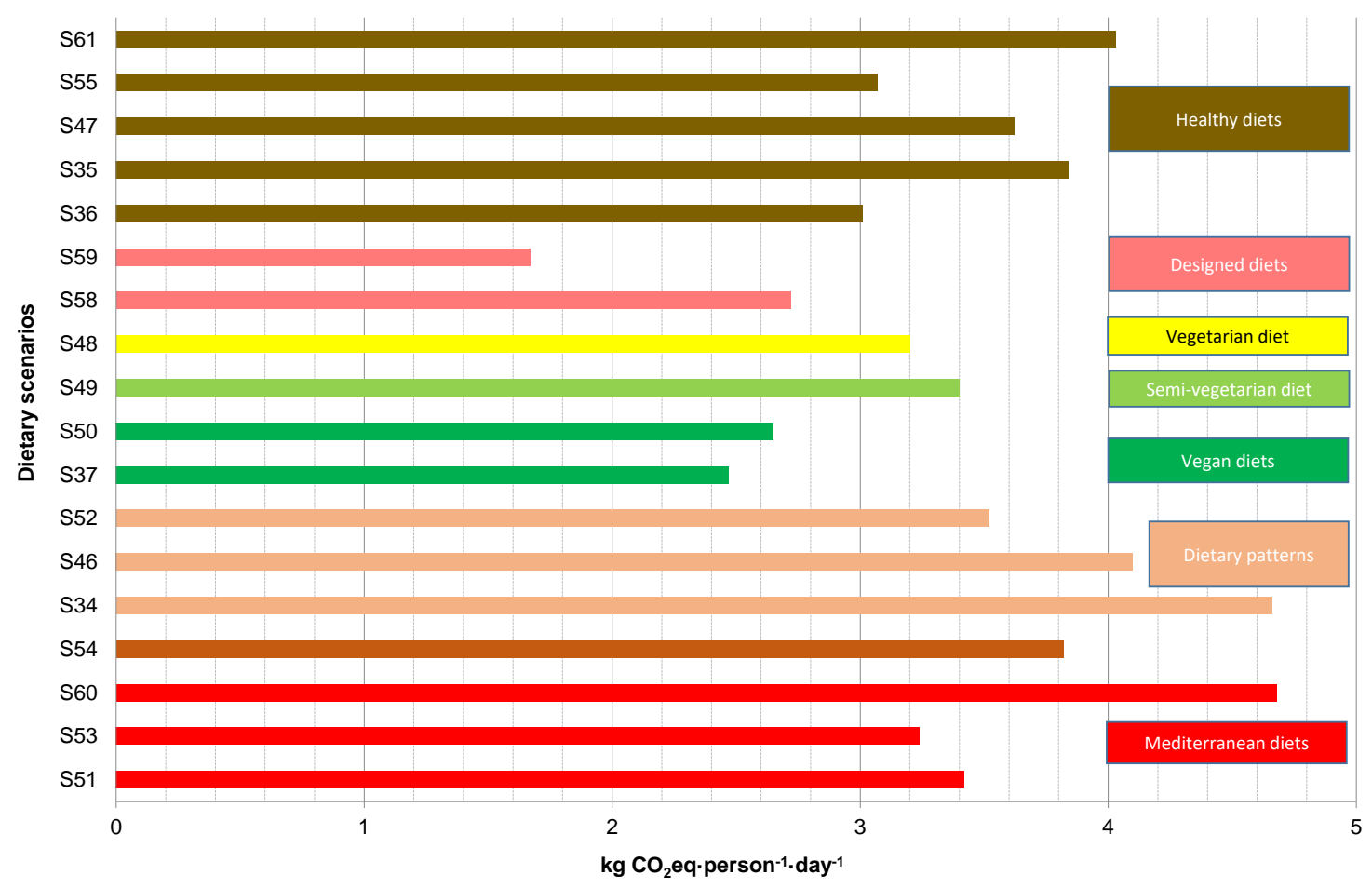

The designed diet based on low GHGs emission (S59) -e.g. prioritizing the consumption of organic food, reported the best profile followed by vegan diets and vegetarians. Regarding the Mediterranean diets, the three scenarios correspond to Mediterranean-style diet performed in non-Mediterranean countries. S60 reported till 1.4 times higher GHGs emission than the others mainly due to ingestions of foodstuffs. In addition, outstanding variations were identified in the daily energy intakes. 
Finish (S34) and Dutch (S46 and S52) dietary patterns were also analysed. The Finish scenario derived the worst environmental profile mostly due to the reported daily consumption amount of milk (1082g in S34 vs 330g in S46 and S52).

Regarding healthy diets, designed following sanitary recommendations in the corresponding countries (Finland and The Netherlands), S47 and S35 are in line in terms of GHGs emission in spite of belong to different countries. It is due to not remarkable differences on the ingestion of the basic ingredients such as dairy products, meat, fish and bread. S36 (a designed diet) is a modification of S35, totally excluding the consumption of milk and ruminant meat. Its environmental profile considerably was improved. In this group of healthy diets, it has been included the Asian-style diet (S61), which is receiving increasing relevance in New Zealand due to growth of Asian population (Wilson et al., 2013) and considered a health dietary pattern to be promoted. It derived on a high carbon footprint score $\left(4.03 \mathrm{~kg} \mathrm{CO}\right.$ eq. person $\left.{ }^{-1} \cdot \mathrm{day}^{-1}\right)$. It is impossible to identify the responsible factors of that score due to the lack of information in the consulted manuscript (Wilson et al., 2013).

Just as a final remark, regardless the system boundaries, the results confirm that a reduction of carbon footprint in daily diets requires a decrease of meat and dairy products consumption, since both can be considered as the environmental hotpots in terms of GHGs emission. However, when evaluating different diets and alternatives are being weighed, the assessment of the nutritional quality is mandatory since the supply of micronutrients could be neglected.

\subsection{Nutrient Rich Diet score}

The health benefits from diets are difficult to identify due to diets are highly complex and are continuously under public debate. In this study, the NRD9.3 score have been selected to identify nutritionally healthy diets. Its concept is useful for evaluating the nutritional quality of diets. The choice of the nine nutrients to encourage and the three nutrients to limit has been in line with previous studies where this score was validated (van Kernebeek et al., 2014; Röös et al., 2015; Castañé and Antón, 2017). However, this score could not be estimated for all the scenarios proposed for comparison due to the lack of information either nutrients intake specification or diet composition in terms of foodstuffs. Only valuable nutrients data were identified for twelve scenarios (S1-S3, S31-S37, S62-S63) of the 66 considered in this review 
(Risku-Norja et al., 2009; Pathak et al., 2010; Saxe et al., 2013; Castañé and Antón, 2017; Esteve-Llorens et al., 2018). Table 2 shows the NRD9.3 scores for these twelve scenarios considering different references regarding the recommended daily intakes of nutrients.

Table 2. Nutrient Rich Diet (NRD9.3) scores estimated for the scenarios with available information regarding nutrients composition. ${ }^{ \pm}$RDV from EFSA (2010; 2012); ${ }^{\sharp}$ RDV from Castañé and Antón (2017); ' RDV from Fundación Española de la Nutrición (2004).

\begin{tabular}{llccc}
\hline & Diet scenario & NRD9.3 & NRD9.3 & NRD9.3 $^{\boldsymbol{\alpha}}$ \\
\hline S1 & Atlantic diet & 613 & 411 & 603 \\
\hline S2 & Mediterranean diet & 635 & 389 & 624 \\
\hline S3 & Vegan diet & 678 & 469 & 638 \\
\hline S31 & Danish dietary pattern & 384 & 112 & 315 \\
\hline S32 & Healthy diet & 396 & 139 & 344 \\
\hline S33 & New Nordic diet & 264 & 48 & 223 \\
\hline S34 & Finish dietary pattern & 552 & 327 & 454 \\
\hline S36 & Healthy diet & 607 & 382 & 552 \\
\hline S37 & Modified diet & 642 & 410 & 578 \\
\hline S62 & Vegan diet & 666 & 442 & 590 \\
\hline S63 & Non-vegetarian diet & 582 & 424 & 497 \\
\hline
\end{tabular}

Variations on the scores depend on the recommended values summarised in Table 1, which could be surprisingly different based on the basis considered (e.g. see discrepancies on Vitamin A, protein or Vitamin C). In addition, the ranking of diets lightly changes regarding the reference considered for the score estimation. Regardless the RDV-reference considered, the worse positions in the ranking are always occupied by S31-S33 (see Figure 4). It should be highlighted here that S33 corresponds to the New Nordic diet, the Scandinavian variant of the Mediterranean diet (Saxe et al., 2013). This diet reports a high daily energy intake (3,095 kcal) and a high ingestion of nutrients to limit such as sodium and saturated fat (van Kernebeek et al., 2014), which reduces the nutritional score.

With regard to the top position (See Figure 4), it is always occupied by S3 (vegan diet) regardless the reference considered for the nutrients intake and in line with other healthy scores considered in the literature (van Dooren et al., 2014). This vegan diet reported the highest nutritional score, even higher than the Atlantic (S1) and Mediterranean (S2) diets, known as 
healthy diets. The rationale behind this high score can be explained by the higher consumption of nutrients to encourage and the lower intake of nutrients to limit (e.g. sodium and saturated fat) in this diet in comparison with others. However, the scores for the Atlantic and Mediterranean diets are also outstanding (higher than other type of diets) mostly due to their particular characteristics (both promote the consumption of vegetables, fruits, olive oil, fresh products and food not much processed). Both (S1 and S2) are also in top positions if RDV following the suggestions from Fundación Española de la Nutrición (2004) are considered 8see Figure 4).

The modified diet proposed by Risku-Norja et al. (2009) in which milk based products are totally excluded as well as the consumption of ruminant meat (S36) also reported a high NRD9.3 score in line to the Mediterranean diet if EFSA recommendations are taken into consideration. This diet (S36) promotes the consumption of alternative foodstuffs such as oat and barley, deriving on high intake of nutrients to encourage.

Figure 4. Association between Carbon footprint ( $\left.\mathrm{kg} \mathrm{CO}_{2} \mathrm{eq} \cdot \mathrm{day}^{-1}\right)$ and NRD9.3 score per capita of selected dietary choices. a) RDV from EFSA (2010; 2012); b) RDV from Castañé and Antón (2017); c) RDV from Fundación Española de la Nutrición (2004). Blue points correspond to Cultivation-to-retail approach; Red points correspond to cultivation-to-farm gate approach; Green points correspond to Cultivation-to-consumer approach.

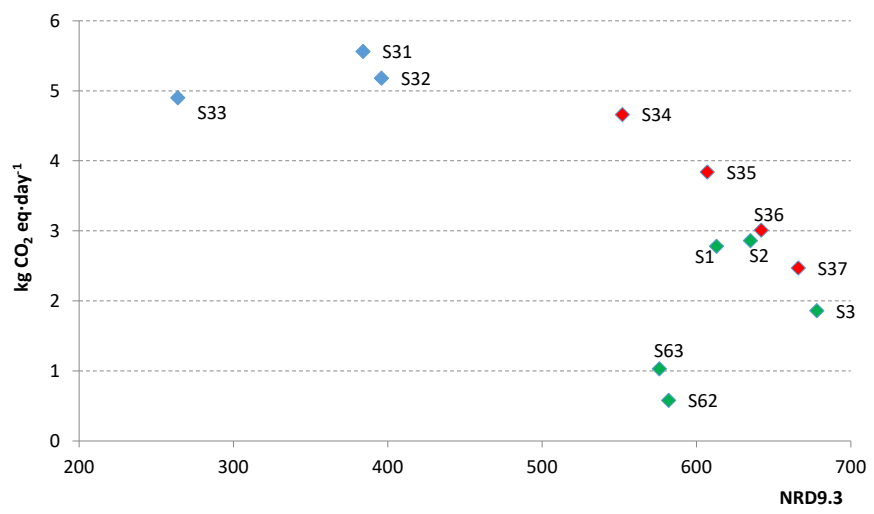




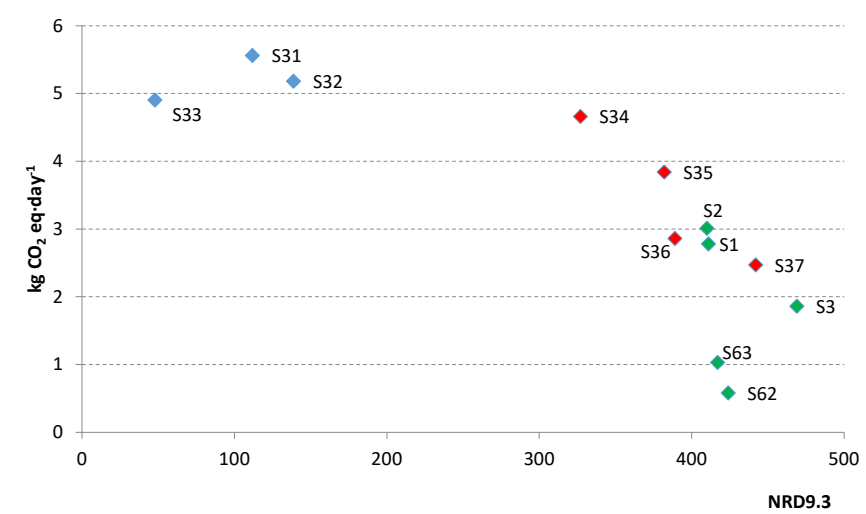

b

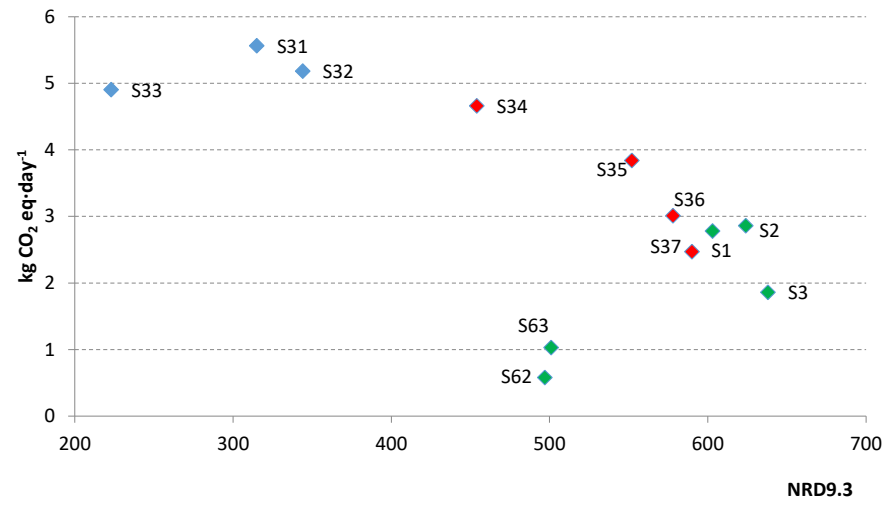

C

\subsection{Climate change per Nutrient Rich Diet score}

Food and Agriculture Organisation of the United Nations (FAO, 2010) considers that a sustainable diet must present a low associated environmental impact and be nutritionally adequate at the same time that optimises natural and human resources and guarantee nutrition security (FAO, 2010). Thus and according to that definition, it is combined both healthy and environmental pillars. Therefore, these diets that involve high NRD9.3 scores and low GHGs emissions should be considered in the proposal of guidelines to promote dietary recommendations.

Figure 5 shows the results obtained for an index based on the estimation of GHGs emissions per NRD9.3 score. Indian diets (S62 and S63) derive on the lowest indexes, followed by the vegan (S3), Mediterranean (S2) and Atlantic (S1) diets in spite of considering a cultivation-toconsumer approach. This result supports the efforts made by sanitary groups to promote the dietary choices towards Mediterranean diet parameters, characterised by high levels of plant based products (vegetables, legumes and fruits) as well as by the consumption of olive oil as the main source of dietary fat (Li et al., 2016). Regarding vegan diet there are discrepancies. 
Although it reports higher score in sustainability (van Dooren et al., 2014), some barriers have been found regarding the supply of some recommended nutrients such as iron, calcium as well as vitamin D and B12 (ADA, 2009; van Dooren et al., 2014). In this sense, fortified foods or supplements should be incorporated to the vegan habits to provide the adequate intake of these nutrients (USDA, 2010).

On the other hand, diets proposed by Saxe et al. (2013) reported the worse profiles due to the large carbon footprints (in spite of considering cultivation-to-retailer approach) and the low nutrient score. These diets are characterised by high daily energy intakes as well as nutrients to limit (e.g., sodium and sugar). Moreover, they reported a large consumption of animal based products such as meat, even in the New Nordic Diet (S33), considered the Scandinavian variant of the Mediterranean diet (van Dooren et al., 2016)

Figure 5. Daily index of carbon footprint ( $\left.\mathrm{gCO}_{2} \mathrm{eq}\right)$ per nutrient score (NRD9.3) per capita. A RDV from EFSA (2010; 2012); B - RDV from Castañé and Antón (2017); C - RDV from Fundación Española de la Nutrición (2004).

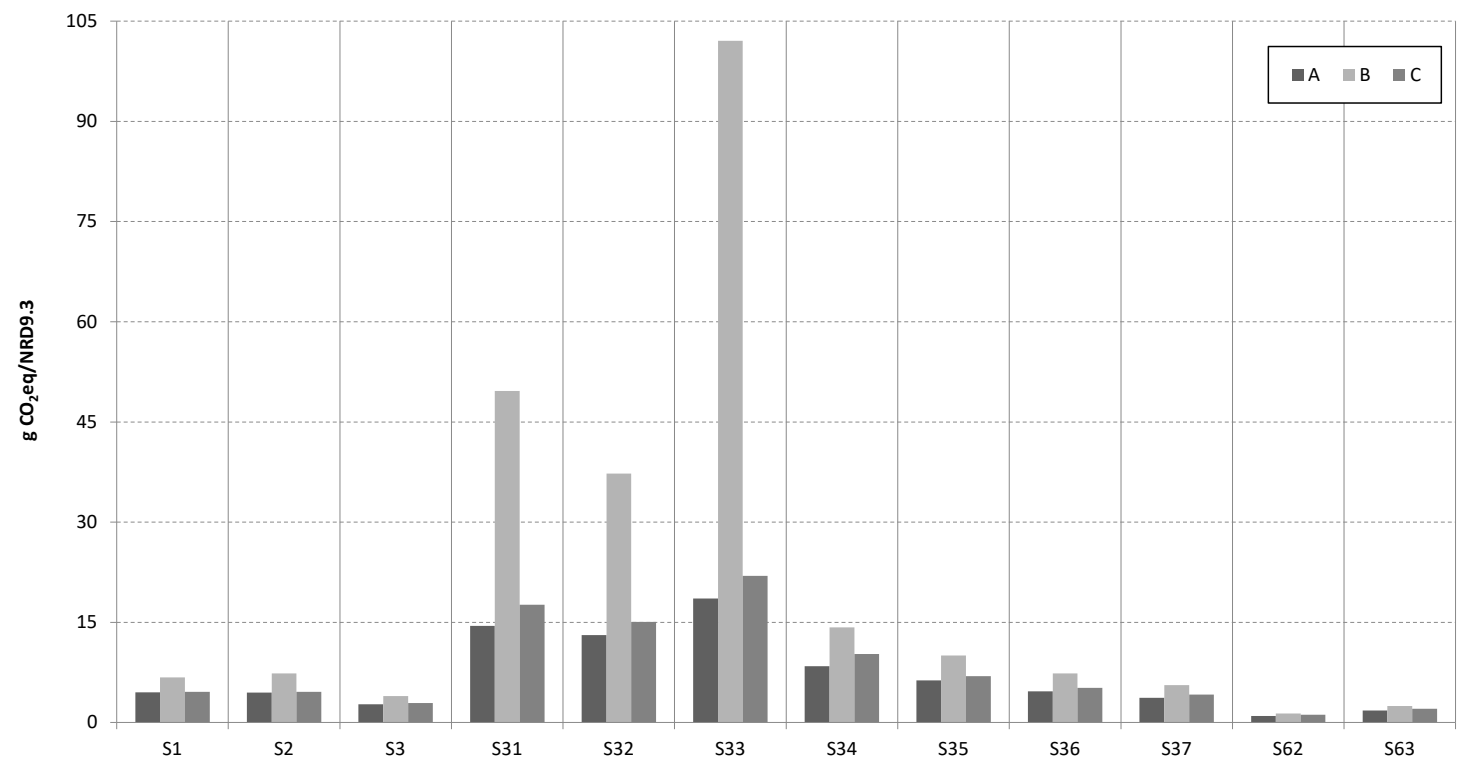

\subsection{Global comparison per country clusters}

According to the literature and sanitary recommendations (EFSA, 2009; FAO, 2014), 2,000 kcal is advised for inactive adult women to maintain energy balance in European countries. However, the rank of energy requirements per capita identified in the literature ranges from 1,702 kcal.person-1. day-1 (Pathak et al., 2010) in the Indian diets to $3,095 \mathrm{kcal} \cdot$ person $^{-1} \cdot$ day $^{-1}$ 
(Saxe et al., 2013) in Denmark. A detailed identification of diets and corresponding caloric intake is shown in Table A2. Outstanding differences can be also reported between clusters of countries, being the highest energy intakes identified in NE (2,197-3,095 kcal per person and day). These variations between regions are mainly affected by their consumption habits. Therefore, the relatively high consumption of vegetables, legumes and grains as well as low consumption of animal based products (mainly animal fat since it is substituted by olive oil) characteristic of SE-countries is behind of their lower caloric values (Tukker et al., 2011).

However, for the direct comparison between daily diets, all of them have been adjusted to an equalised daily intake of 2,000 kcal. This perspective has also been considered by other authors (Van Dooren et al., 2014; van de Kamp et al., 2018) giving insight into differences in carbon footprint directly derived from differences on the diet composition. Figure 6 displays, per country clusters, the carbon footprints of the dietary choices selected for analysis adjusted to 2,000 kcal. Seven scenarios (S7-S11, S18-S19) have been excluded from the comparison due to the lack of information regarding their caloric intakes per day.

Figure 6. Carbon footprint of adjusted diets to $2,000 \mathrm{kcal}$. Bars in black correspond to recalculations under a cultivation-to-farm gate approach. 




It is important to bear in mind that although the effect of both the system boundaries (cultivation to consumer, retailer or farm gate) and other methodological assumptions (e.g., hybrid method and data sources) is noticeable on the results, as previously discussed, the composition of the diets (and amount of foodstuffs intake) is the main responsible issue of differences on the carbon footprints.

According to Berlin and Sund (2010), contributions to the total GHGs emission from consumption stage (that is, transportation from retailer to household and home cooking) in cultivation-to-consumer approach is around 10\%. Esteve-Llorens et al. (2018) reported an average contribution of around 14\% from that phase and around 3\% for the distribution phase which includes transportation till retailers. Thus, the contribution from both distribution and consumption phases have been removed from the carbon footprints to facilitate the comparison 
(cultivation-to-farm gate approach in all scenarios) and in line with Tukker and colleagues (Tukker et al., 2011) who reported that their effect is similar in all diet scenarios. Figure 6 also displays the new estimated GHGs based profiles. Applying that restriction the average carbon footprint per day and person is $3.33 \pm 1.87 \mathrm{kgCO}_{2}$ eq taking into account 59 dietary scenarios. As expected, dietary choices from SE and other countries such as India and Peru together with vegan and vegetarian diets are linked to the best environmental profiles. Regardless the country cluster, vegan diets do not derive on outstanding deviations on the carbon footprint $\left(2.23 \pm 0.51 \mathrm{kgCO}_{2} \mathrm{eq} \cdot \mathrm{day}^{-1} \cdot\right.$ person $\left.^{-1}\right)$. On the contrary, differences can be highlighted in the vegetarian diets $\left(2.16 \pm 1.57 \mathrm{kgCO}_{2} \mathrm{eq} \cdot \mathrm{day}^{-1} \cdot\right.$ person $\left.^{-1}\right)$. The rationale behind it is related to different dietary guidelines depending on the countries.

Dietary choices from NE and WE countries reported around $3.50 \pm 1.10 \mathrm{kgCO}_{2}$ eq and $3.53 \pm 0.8 \mathrm{kgCO}_{2}$ eq per day and capita respectively. In both clusters, the results are affected by the largest ingestion of dairy products and red meat, excluding vegan and vegetarian diets.

According to the literature review, estimations for carbon footprint of diets can considerably vary even up to four times (e.g.,S4 and S5) even considering the same system boundaries to calculate the GHGs emission. The consideration of different approaches regarding foreground and background data sources (i.e., data from statistical consumptions or data according to sanitary recommendations), transport mode and distances as well as production systems can derive on underestimations. Thus, the use of appropriate system boundaries as well as the definition of methods that allow a correct trade-off between available data sources and accurate results is mandatory mostly in decision making strategies focused on diets.

According to the results displayed in Figure 6 and Table A1, carbon footprint can decrease till $30 \%$ when changing from average dietary pattern to a healthy diet (e.g., S20 vs S21). In this line, reduction of $60 \%$ could be achieved changing from diets rich on meat based products to vegan diets (e.g., S13 vs S14). This large decrease can be explained by the fact that vegan diet is considered also an example of healthy diet (Pernollet et al., 2017).

\subsection{Decision support for sustainable and healthy diets}

The comparative analyses previously reported show that the composition of diets is the main responsible of variations identified in carbon footprints. Thus, possibilities to reduce GHGs 
emission based on changes of foodstuffs and dietary habits could be proposed. In this sense, diet and sustainability are closely connected.

Shifting from animal based to plant based products is supported by numerous studies (Garnett, 2011; Dagevos and Voordouw, 2013; Hoolohan et al., 2013; Westhoek et al., 2014) as the best choice to reduce GHGs emission and from a sustainability viewpoint. However, this option must be analysed in detail since some plant based foodstuffs such as rice could emit surprising GHGs emission. If consumption of rice is presented as an alternative ingredient, special attention should be paid into the cultivation strategy (Pathak et al., 2010; Fusi et al., 2017). Regarding meat consumption, the type of animal considerably affects the GHGs emission and dietary patterns including meat can be also considered as an example of sustainable and healthy diets. In this sense, monogastric meats have smaller carbon footprints than ruminant based meats (Westhoek et al., 2014). Thus, the consumption of red meat is a decisive parameter of the carbon footprint (Hallström et al., 2015). Substitution of animal based protein by alternative foodstuffs such as pulses and legumes could also be considered as an improvement (Pathak et al., 2010). In this sense, attention can be paid into the so-called superfoods such as quinoa, a food product rich on protein of which ingestion (while removing meat) could derive on outstanding reductions of GHGs emissions (Vázquez-Rowe et al., 2017). Satisfying daily energy requirements by increasing the ingestion of fruits and vegetables (isocaloric substitution of animal based protein) have not only environmental but also healthy benefits. However, in case of considering any of these proposals, further attention should be paid into the intake of micro-nutrients, the corresponding nutritive values and getting a balanced diet. A balanced diet supplies the energy and nutrients by means of the ingestion of different and valuable foods in adjusted quantities. Finally, it is also important to bear in mind that only eating the necessary amounts of food is a priority measure to reduce GHGs emission from dietary habits (Garnett, 2011).

Therefore, several considerations regarding environmentally and healthfully sustainable eating are worth noting always taking in mind that consumer preferences depends not only on environmental and health issues but also on lifestyles and trends. Public procurement policies are required to raise awareness not only of society but also food manufacturers and food 
businesses. Social campaigning for promoting the benefits from environmental sustainable diets should also require advises and cultural formation based activities.

Attention should be paid into the incorporation of food taxes (Westhoek et al., 2014) although it should be analysed with care. Vinnari and Tapio (2012) proposed a direct taxation (consumption taxes) in livestock based products (i.e., increasing the price of meat and dairy products) motivated either by environmental or ethical issues. It could address not only to reduce these products consumption but also to the optimisation of their manufacturing processes with the aim of achieving the reduction of their environmental profiles. Taxing the environmental effects derived from foodstuffs production was also proposed as an efficient policy instrument to deal with GHGs emission (Wirsenius et al., 2011).

Promoting the reduction of meat and dairy products by means of increasing consumption of plant based products is an interesting alternative to mitigate GHGs emission. However, it could mean that the final goal should be a society that would give up animal based products eating to be a vegan society. In this sense, it is well-known that definition of vegan diet (even vegetarian one) is in conflict with the FAO definition of sustainable diet since it is neither nutritionally adequate (some required micro-nutrients are not supply) nor culturally accepted by general society (van Dooren et al., 2014). Therefore, "a sustainable" reduction should be based on the consumption of alternative products which could contribute to satisfy the recommended daily values of nutrients. It is the case of protein rich foodstuffs such as quinoa and pulses, whole grain cereals and shifting from animal to vegetable fats (e.g., olive oil).

\section{Conclusions}

What we eat plays an important role in the evaluation of the sustainability of people's lifestyles. It is well-known that meat and dairy products consumption contributes significantly to GHGs emission being the most GHGs-intensive foodstuffs. However, complete removal of animal based products from the daily diet is not realistic in many cultures and could derive on nohealthy habits.

This review has largely focused on the comparative assessment of both carbon footprint and nutritional quality of reported dietary choices (daily diets) available in the literature. 
This study shows that diets with high nutritional score based on NRD9.3 score such as Mediterranean and Atlantic as well as vegan diets also have high sustainability scores (i.e., low carbon footprints). Indian and Peruvian diets report the best carbon footprint scores mainly due to their characteristic composition rich on the remarkable ingestion of plant-based products such as pulses, grains and vegetables as well as the low intake of livestock based products. Dietary choices from Northern and Western Europe countries derive on the largest carbon footprints mostly due to outstanding consumption of dairy products. Moreover, diets adhering to food based dietary guidelines (i.e., healthy diets) did not always derive on lower GHGs emission rates.

In line with the results, shifting the intake of ruminants based meat to a moderate consumption of chicken, pork and poultry meat, the iso-caloric substitution (partial no total) of animal based protein by other foodstuffs such as quinoa and legumes as well as the promotion of olive oil ingestion may be consistent with a more environmentally and healthfully friendly diet.

Many of these consulted studies use different system boundaries, ignoring important life cycle stages and underestimating GHGs emissions. Thus, challenges should be beard in mind to improve environmental impact of the food system without reducing the health impact of nutrition. Efforts should be also paid into the development of consistent and agreed methods to estimate both carbon footprint and nutritional quality based scores to avoid discrepancies and to reduce uncertainties in the comparisons. Moreover, policies could be developed to support consumers in making both more environmental sustainable and healthier dietary choices.

\section{Acknowledgements}

This research has been supported by a project granted by Xunta de Galicia (project ref. ED431F 2016/001). Dr. S. González-Garcia would like to express her gratitude to the Spanish Ministry of Economy and Competitiveness for financial support (Grant reference RYC-201414984). The authors belong to the Galician Competitive Research Group GRC 2013-032 as well as to CRETUS (AGRUP2015/02), co-funded by Xunta de Galicia and FEDER.

\section{References}


ADA, 2009. Position of the American dietetic association: vegetarian diets. J. Am.Diet. Assoc. 109, 1266-1282

Aleksandrowicz, L., Green, R., Joy, E.J.M., Smith, P., Haines, A., 2016. The Impacts of Dietary Change on Greenhouse Gas Emissions, Land Use, Water Use, and Health: A Systematic Review. Plos One 11(11), e0165797. doi:10.1371/journal.pone.0165797

Amcoff, E., Edberg, A., Enghardt Barbieri, H., Lindroos, A.K., Nä Isén, C., Pearson, M., Warensjö Lemming, E., 2012. Livsmedels- och nä ringsintag bland vuxna i Sverige. Riksmatenvuxna 2010-11. (The food and nutrient intake among adults in Sweden. Riksmaten-adults 2010-11).Swedish Food Agency, Uppsala, Sweden.

Astrup, A., Andersen, N.L., Stender, S., Trolle, E., 2005. The Danish Dietary Recommendations 2005. Denmark: Ernæringsrådet og Danmarks Fødevareforskning; 2005

Baroni, L., Cenci, L., Tettamanti, M., Berati, M., 2007. Evaluating the environmental impact of various dietary patterns combined with different food production systems. Eur. J. Clin. Nutr. 61, 279-286. doi:10.1038/sj.ejcn.1602522

Berlin, J., Sund, V., 2010. Environmental Life Cycle Assessment (LCA) of Ready Meals, SIK-Report No. 804. The Swedish Institute for Food and Biotechnology AB

Blauert, E., Holt, M.H., Mithril, C., Meyer, C., 2010. Basis of the New Nordic Diet. University of Copenhagen. http://foodoflife.ku.dk/opus/english/wp/nordic_diet/basis_nnd/

Calvo-Malvar, M. del M., Leis, R., Benítez-Estévez, A.J., Sánchez-Castro, J., Gude, F., 2016. A randomised, family-focused dietary intervention to evaluate the Atlantic diet: the GALIAT study protocol. BMC Public Health 16, 820. doi:10.1186/s12889-016-3441-y

Carlsson-Kanyama, A., Gonzalez, A.D., 2009. Potential contributions of food consumption patterns to climate change. Am J Clin Nutr. 89, 1704S_9.

Castañé, S., Antón, A., 2017. Assessment of the nutritional quality and environmental impact of two food diets: A Mediterranean and a vegan diet. J. Clean. Prod. 167, 929-937. doi:10.1016/j.jclepro.2017.04.121 
Dagevos, H., Voordouw, J., 2013. Sustainability and meat consumption: is reduction realistic?. Sustainability: Science, Practice \& Policy 9 (2), 1-10.

Dahlqvist, A., Höglund, M., 2009. Doktor Dahlqvists och Airams LCHF-kokbok. (Dr Dahlqvist's and Airam's LCHF-cookbook).Pagina Förlags AB/Optimal Förlag, ISBN: 978-917241-725-0.

De Ruiter, H., Kastner, T., Nonhebel, S., 2014. European dietary patterns and their associated land use: Variation between and within countries. Food Pol. 44: 158-166. https://doi.org/10.1016/j.foodpol.2013.12.002

DGE, 2008. Vollwertig essen und trinken nach den 10 Regeln der DGE; aid infodienst und Deutsche Gesellschaft für Ernährung DGE: Bonn, Germany.

Drewnowski, A., 2009. Defining nutrient density: Development and validation of the nutrient rich foods index. J. Am. Coll. Nutr. 28, 421S-426S. doi:10.1080/07315724.2009.10718106

Duchin, F., 2005. Sustainable Consumption of Food - A Framework for Analyzing Scenarios about Changes in Diets. J. Ind. Ecol. 9, 99-114. doi:10.1162/1088198054084707

EFSA, 2009. Review of labelling reference intake values Scientific Opinion of the Panel on Dietetic Products, Nutrition and Allergies on a request from the Commission related to the review of labelling reference intake values for selected nutritional elements 1 Adop.

EFSA, 2010. EFSA panel on dietetic products, nutrition, and allergies (NDA); scientific opinion on dietary reference values for carbohydrates and dietary fibre. EFSA J. 8, 1462 [77 pp.].

EFSA, 2012. EFSA panel on dietetic products, nutrition and allergies (NDA); scientific opinion on dietary. Reference values for protein. EFSA J. 10, 2557 [66 pp.].

ENAPREF, 2012. Perú: Consumo per cápita de los principales alimentos 2008-2009. Encuesta Nacional de Presupuestos Familiares (ENAPREF). Dirección Técnica de Demografía e Indicadores Sociales. Instituto Nacional de Estadística e Informática (INEI). [in Spanish] 
Esteve-Llorens, X., Darriba Ferradás, L.C., Moreira, M.T., Feijoo, G., González-García, S., 2018. Towards an environmentally sustainable Atlantic dietary pattern: life cycle carbon footprint and nutritional quality. Environmental Research. under review.

Estruch, R., Martínez-González, M.A., Corella, D., Salas-Salvadó, J., Ruíz-Gutierrez, V., Covas, M.I., Flol, M., Gómez-Gracia, E., López-Sabater, M.C., Vinyoles, E., Arós, F., Conde, M., Lahoz, C., Lapetra, J., Sáez, G., Ros, E., 2006. Effects of a Mediterranean-Style Diet on Cardiovascular Risk Factors. A Randomized Trial. Ann. Intern. Med.145 (1), 1-11.

FAO, 2010. Biodiversity and Sustainable Diets United Against Hunger. International Scientific Symposium, FAO Headquarters, Rome.

FAO, 2014. Necesidades Nutricionales del Ser Humano, FAO.

Friel, S., Dagour, A., Garnett, T., Lock, K., Chalabi, Z., Roberts, I., Butler, A., Butler, C.D., Waage, J., McMichael, A.J., Haines, A., 2009. Public health benefi ts of strategies to reduce greenhouse-gas emissions: food and agriculture. The Lancet 374 (9706): 2016-2025. doi:10.1016/S0140-6736(09)61753-0

Fulgoni, V.L., Keast, D.R., Drewnowski, A., 2009. Development and Validation of the Nutrient-Rich Foods Index: A Tool to Measure Nutritional Quality of Foods. J. Nutr. 139, 1549_ 1554. doi:10.3945/jn.108.101360

Fundación Española de la Nutrición, 2004. Consumo de alimentos en Galicia. La dieta atlántica. Madrid.

Fusi, A., González-García, S., Moreira, M.T., Fiala, M., Bacenetti, J., 2017. Rice fertilised with urban sewage sludge and possible mitigation strategies: an environmental assessment. J.Clea.Prod. 140, 914-923

Garnett, T., 2011. Where are the best opportunities for reducing greenhouse gas emissions in the food system (including the food chain)? Food Policy 37, 463-466.

Guallar-Castillón, P., Oliveira, A., Lopes, C., López-García, E., Rodríguez-Artalejo, F., 2013. The Southern European Atlantic Diet is associated with lower concentrations of markers of coronary risk. Atherosclerosis 226, 502-509. 
Hallström, E.,Carlsson-Kanyama, A., Börjesson, P., 2015. Environmental impact of dietary change: a systematic review. J. Clean. Prod. 91, 1-11. https://doi.org/10.1016/j.jclepro.2014.12.008

Hawkesworth, S., Dangour, A.D., Johnston, D., Lock, K., Poole, N., Rushton, J., Uauy, R., Waage, J., 2010. Feeding the world healthily: the challenge of measuring the effects of agriculture on health. Phil. Trans. R. Soc. B 365: 3083-3097. doi:10.1098/rstb.2010.0122

Health Council, 2006. Guidelines for Good Nutrition 2006 (in Dutch). Gezondheidsraad, The Hague, Netherlands.

Helakorpi, S., Patja, K., Prättälä, R., Aro, A., Uutela, A., 2003. Health Behaviour and Health among Finnish Adult Population, Spring 2003, National Public Health Institute, Helsinki

Heller, M. C., Keoleian, G. A., 2003. Assessing the sustainability of the U.S. food system: A life cycle perspective. Agric. Syst. 76 (3), 1007-1041

Heller, M.C., Keoleian, G.A., Willett, W.C., 2013. Toward a life cycle-based, diet-level framework for food environmental impact and nutritional quality assessment: a critical review. Env. Sci Technol 47, 12632-12647. doi:10.1021/es4025113

Hoolohan, C., Berners-Lee, M., McKinstry-West, J., Hewitt, C.N., 2013. Mitigating the greenhouse gas emissions embodied in food through realistic consumer choices. Energy Policy 63, 1065-1074. http://dx.doi.org/10.1016/j.enpol.2013.09.046

ISO 14040, 2006. Environmental management — Life cycle assessment — Principles and framework, Iso 14040. Switzerland. doi:10.1136/bmj.332.7550.1107

Jungbluth, N., Tietje, O., Scholz, R.W., 2000. Food purchases: Impacts from the consumers' point of view investigated with a modular LCA. Int. J. Life Cycle Assess. 5, 134142. doi:10.1007/BF02978609

Li, Q., Li, T., Liu, C., Chen, J., Zhang, R., Zhang, Z., Dai, T., McClements, D.J., 2016. Potential physicochemical basis of Mediterranean diet effect: Ability of emulsified olive oil to increase carotenoid bioaccessibility in raw and cooked tomatoes. Food Research International $89,320-329$ 
Meier, T., Christen, O., 2013. Environmental Impacts of Dietary Recommendations and Dietary Styles: Germany As an Example. Environmental Science \& Technology47, 877-888. dx.doi.org/10.1021/es302152v

Menotti, A., Keys, A., Kromhout, D., Nissinen, A., Blackburn, H., Fidanza, F., et al., 1990. Twenty-five-year mortality from coronary heart disease and its prediction in five cohorts of middle-aged men in Finland, The Netherlands, and Italy. Prev Med.19, 70-78. [PMID:2377589]

MINSA, 2012. Tablas Peruanas de Composición de Alimentos. Centro Nacional de Alimentación y Nutrición Instituto Nacional de Salud, Peru. ISBN: 978-9972-857-73-7

Mithril, C., Dragsted, L.O., Meyer, C., Blauert, E., Holt, M.K., Astrup, A., 2012. Guidelines for the New Nordic Diet. Public Health Nutrition. doi:10.1017/S136898001100351X

MRI, 2008. National Nutrition Survey II (Nationale Verzehrsstudie II: Ergebnisbericht Die bundesweite Befragung zur Ernährung von Jugendlichen und Erwachsenen); Max RubnerInstitute: Karlsruhe, Germany.

Muñoz, I., Milà I Canals, L., Fernández-Alba, A.R., 2010. Life cycle assessment of the average Spanish diet including human excretion. Int. J. Life Cycle Assess. 15, 794-805. doi:10.1007/s11367-010-0188-z

National Food Administration, 1997. Svenska Na"ringsrekommendationerna: SNR 97 (Swedish Nutritional Recommendations) (in Swedish).

National Food Administration, 1999. Riksmaten 1997/98 (Sweden's food 1997/98), http://www.slv.se/download/document/approveddocs/na_riksmat_vf199_namnen.htm (in Swedish).

Nelson, V., 2016. Peru's image as a culinary destination. J Cult Geography 33(2), 208228.

Norden, 2014. Nordic Nutrition Recommendations 2012; Integrating nutrition and physical activity. Nordic Council of Ministers, Copenhagen, Denmark 
Nordic Council, 2004. Nordic Nutrition Recommendations 2004-integrating nutrition and physical activity.http://www.norden.org/da/publikationer/publikationer/2004-013.

Pairotti, M.B., Cerutti, A.K., Martini, F., Vesce, E., Padovan, D., Beltramo, R., 2015. Energy consumption and GHG emission of the Mediterranean diet: A systemic assessment using a hybrid LCA-IO method. J. Clean. Prod. 103, 507-516. doi:10.1016/j.jclepro.2013.12.082

Pathak, H., Jain, N., Bhatia, A., Patel, J., Aggarwal, P.K., 2010. Carbon footprints of Indian food items. Agric. Ecosyst. Environ. 139, 66-73. doi:10.1016/j.agee.2010.07.002

Pernollet, F., Coelho, C.R.V., van der Werf, H.M.G., 2017. Methods to simplify diet and food life cycle inventories: Accuracy versus data-collection resources. J. Clean. Prod. 140, 410420. doi:10.1016/j.jclepro.2016.06.111

Ran, Y., van Middelaar, C.E., Lannerstad, M., Herrero, M., de Boer, I.J.M., 2017. Freshwater use in livestock production-To be used for food crops or livestock feed?. Agricultural Systems 155, 1-8. https://doi.org/10.1016/j.agsy.2017.03.008

Risku-Norja, H., 2011. From environmental concerns towards sustainable food provisioning. Material flow and food consumption scenario studies on sustainability of agri-food systems.

Risku-Norja, H., Kurppa, S., Helenius, J., 2009. Dietary choices and greenhouse gas emissions - assessment of impact of vegetarian and organic options at national scale. Progress in Industrial Ecology - An International Journal 6(4), 340-354.

Röös, E., Karlsson, H., Witthöft, C., Sundberg, C., 2015. Evaluating the sustainability of diets-combining environmental and nutritional aspects. Environ. Sci. Policy 47, 157-166. doi:10.1016/j.envsci.2014.12.001

Sáez-Almendros, S., Obrador, B., Bach-Faig, A., Serra-Majem, L., 2013. Environmental footprints of Mediterranean versus Western dietary patterns: beyond the health benefits of the Mediterranean diet. Environ. Health 12, 118. doi:10.1186/1476-069X-12-118 
Saxe, H., Jensen, R.B., Petersen, M.L., 2006. Fødevarers Miljøeffekter. Det politiske ansvar og det personlige valg. Institute of Environmental Assessment. English abstract. http://www.dors.dk/graphics/Synkron-Library/Publikationer/IMV/2006/fdevare.pdf. (in Danish)

Saxe, H., Larsen, T.M., Mogensen, L., 2012. The global warming potential of two healthy Nordic diets compared with the average Danish diet. Clim. Change 116, 249-262. doi:10.1007/s10584-012-0495-4

Scarborough, P., Appleby, P.N., Mizdrak, A., Briggs, A.D.M., Travis, R.C., Bradbury, K.E., Key, T.J., 2014. Dietary greenhouse gas emissions of meat-eaters, fish-eaters, vegetarians and vegans in the UK. Clim. Change 125, 179-192. doi:10.1007/s10584-014-11691

Smil, V., 2002. Worldwide transformation of diets, burdens of meat production and opportunities for novel food proteins. Enzyme and Microbial Technology 30, 305-311. PII: S0141-0229(01)00504-X

Sonesson, U., Davis, J., Ziegler, F., 2009. Food production and emissions of greenhouse gases-an overview of the climate impact of different product groups. Report by Swedish Institute for Food and Biotechnology presented at the Climate Smart Food Conference, Lund,November23-24, 2009, Swedish Ministry of Agriculture.

Stehfest, E., Bouwman, L., van Vuuren, D.P., den Elzen, M.G.J., Eickhout, B., Kabat, P., 2009. Climate benefits of changing diet. Climatic Change 95, 83-102. doi 10.1007/s10584008-9534-6

Thaler, S., Zessner, M., Weigl, M., Rechberger, H., Schilling, K., Kroiss, H., 2015. Possible implications of dietary changes on nutrient fluxes, environment and land use in Austria. Agricultural Systems 136, 14-29. https://doi.org/10.1016/..agsy.2015.01.006

The Netherlands Nutrition Centre, 2016. Richtlijnen Schijf van Vijf (Guidelines Wheel of Five). The Hague: Voedingscentrum

TNO, 1998. Food Consumption Survey 3 (in Dutch), 1997-1998. TNO/Voedingscentrum, Zeist, Netherlands. 
Tukker, A., Goldbohm, R.A., De Koning, A., Verheijden, M., Kleijn, R., Wolf, O., PérezDomínguez, I., Rueda-Cantuche, J.M., 2011. Environmental impacts of changes to healthier diets in Europe. Ecol. Econ. 70, 1776-1788. doi:10.1016/j.ecolecon.2011.05.001

UGB, 2011. Recommendations for a Whole Food Nutrition; Verband für Unabhängige Gesundheitsberatung e.V. (UGB): Wettenberg/Gießen, Germany.

University of Otago and Ministry of Health, 2011. A Focus on Nutrition: Key findings of the 2008/09 New Zealand Adult Nutrition Survey Wellington: Ministry of Health.

USDA, 2010. Dietary Guidelines for Americans. USDA, the Dietary Guidelines Advisory Committee on the Dietary Guidelines for Americans, Washington DC, USA.

Van de Kamp, M.E., van Dooren, C., Hollander, A., Geurts, M., Brink, E.J., van Rossum, C., Biesbroek, S., de Valk, E., Toxopeus, I.B., Temme, E.H.M., 2018. Healthy diets with reduced environmental impact? - The greenhouse gas emissions of various diets adhering to the Dutch food based dietary guidelines. Food Research International, in press. http://dx.doi.org/10.1016/j.foodres.2017.06.006

Van Dooren, C., Marinussen, M., Blonk, H., Aiking, H., Vellinga, P., 2014. Exploring dietary guidelines based on ecological and nutritional values: a comparison of six dietary patterns. Food Policy 44, 36-46

Van Dooren, C., Aiking, H., 2016. Defining a nutritionally healthy, environmentally friendly, and culturally acceptable Low Lands Diet. Int. J. Life. Cycle. Assess. 21, 688-700.

Van Kernebeek, H.R.J., Oosting, S.J., Feskens, E.J.M., Gerber, P.J., De Boer, I.J.M., 2014. The effect of nutritional quality on comparing environmental impacts of human diets. J. Clean. Prod. 73, 88-99. doi:10.1016/j.jclepro.2013.11.028

Vanham, D., Hoekstra, A.Y., Bidoglio, G., 2013. Potential water saving through changes in European diets. Environment International 61, 45-56. http://dx.doi.org/10.1016/j.envint.2013.09.011 
Van Rossum, C. T. M., Fransen, H. P., Verkaik-Kloosterman, J., Buurma-Rethans, E. J. M., Ocké, M. C., 2011. Dutch National Food Consumption Survey 2007-2010: Diet of children and adults aged 7 to 69 years. Bilthoven: RIVM.

Vaz Velho, M., Pinheiro, R., Sofia, A., 2016. The Atlantic Diet - Origin and features. Int. J. Food Stud. 5, 106-119. doi:10.7455/ijfs/5.1.2016.a10

Vázquez-Rowe, I., Larrea-gallegos, G., Villanueva-rey, P., Gilardino, A., 2017. Climate change mitigation opportunities based on carbon footprint estimates of dietary patterns in Peru 1-25. doi:10.1371/journal.pone.0188182

Vieux, F., Darmon, N., Touazi, D., Soler, L.G., 2012. Greenhouse gas emissions of selfselected individual diets in France: Changing the diet structure or consuming less?. Ecological Economics 75, 91-101.

Vieux, F., Soler, L.G., Touazi, D., Darmon, N., 2013. High nutritional quality is not associated with low greenhouse gas emissions in self-selected diets of French adults. Am. J. Clin. Nutr. 97, 569-83

Vinnary, M., Tapio, P., 2012. Sustainability of diets: From concepts to governance. Ecological Economics 74, 46-54. doi:10.1016/j.ecolecon.2011.12.012

Vraken, L., Avermaete, T., Petalios, D., Mathijs, E., 2014. Curbing global meat consumption: Emerging evidence of a second nutrition transition. Environmental Science \& Policy 39, 95-106. https://doi.org/10.1016/j.envsci.2014.02.009

Wallén, A., Brandt, N., Wennersten, R., 2004. Does the Swedish consumer's choice of food influence greenhouse gas emissions?. Environmental Science \& Policy 7, 525-535. doi:10.1016/j.envsci.2004.08.004.

Werner, L.B., Flysjö, A., Tholstrup, T., 2013. Greenhouse gas emissions of realistic dietary choices in Denmark: the carbon footprint and nutritional value of dairy products. Food \& Nutrition Research, 58 (1), 20687. doi: 10.3402/fnr.v58.20687

Westhoek, H., Lesschen, J.P., Rood, T., Wagner, S., de Marco, A., Murphy-Bokern, D., Leip, A., van Grinsven, H., 2014. Food choices, health and environment: Effects of cutting 
Europe's meat and dairy intake. Global Environmental Change 26, 196-205. http://dx.doi.org/10.1016/j.gloenvcha.2014.02.004

WHO, 2003. Diet, nutrition and the prevention of chronic diseases - report of a Joint WHO/FAO Expert Consultation (No. 916), WHO Technical Report Series. World Health Organization, Geneva.

Wilson, N., Nghiem, N., Mhurchu, C.N., Eyles, H., Baker, M.G., blakely, T., Foods and Dietary Patterns That Are Healthy, Low-Cost, and Environmentally Sustainable: A Case Study of Optimization Modeling for New Zealand. Plos One 8(3), 59648

Wirsenius, S., Hedenus, F., Mohlin, K., 2011. Greenhouse gas taxes on animal food products: rationale, tax scheme and climate mitigation effects. Climatic Change 108, 159-184.

Wolf, O., Pérez-Domínguez, I., Rueda-Cantuche, J.M., Tukker, E., Kleijn, R., de Koning, A., Bausch-Goldbohm, S., Verheijden, M., 2011. Do healthy diets in Europe matter to the environment? A quantitative analysis. J. Pol. Mod. 33, 8-28. doi:10.1016/j.jpolmod.2010.10.009 